Revista lus et Praxis, Año 21, No 1, 2015, pp. 377 - 422

ISSN 0717 - 2877

Universidad de Talca - Facultad de Ciencias Jurídicas y Sociales

"Problemas derivados de la constitución de sindicatos con fines ilícitos:

cuatro cuestiones discutidas"

Raúl Fernández Toledo

Trabajo recibido el 8 de septiembre de 2014 y aprobado el 2 de febrero de 2015

\title{
Problemas derivados de la constitución de sindicatos con fines ilícitos: cuatro cuestiones discutidas
}

\author{
PROBLEMS DERIVED FROM THE CONSTITUTION \\ OF UNIONS WITH ILLICIT PURPOSES: FOUR CONTROVERSIAL ISSUES
}

Raúl Fernández Toledo*

\begin{abstract}
RESUMEN
El presente trabajo persigue dar respuesta a cuatro problemas derivados de la constitución de sindicatos con fines ilícitos (constituidos con abuso del derecho o en fraude a la ley), en que existen opiniones contrapuestas en la jurisprudencia judicial. De esta forma, se persiguen cuatro objetivos vinculados a cuatro problemas de los sindicatos constituidos con fines ilícitos. El primero es determinar el órgano competente del Estado para conocer de las controversias en que se discute si un sindicato fue o no constituido con fines ilícitos. El segundo consiste en establecer cuáles son los sujetos de derecho que tienen legitimación activa para solicitar la sanción de los sindicatos ilícitos, y quiénes pueden ser legitimados pasivos. El tercer objetivo es precisar los instrumentos de que disponen los legitimados activos para solicitar la sanción de un sindicato ilícito y la ineficacia de sus efectos. Y el cuarto es determinar la sanción que corresponde aplicar a los trabajadores que participan en la constitución de un sindicato ilícito.
\end{abstract}

\begin{abstract}
The present work aims to give response to four problems derived from the constitution of unions with illicit purposes (constituted with abuse of rights or with legal fraud), respect to which there exist conflicting views in judicial jurisprudence. Thus, there are four objectives related to four problems of the unions constituted with illicit purposes. The first objective is to determine the competent organ of the State to know about the controversies in which it is discussed if an union was constituted or not with illicit purposes. The second one consists in establishing which are the subjects of right that have active legitimization to request the sanction of the illicit unions, and those who can have passive legal standing. The third aim is to specify the instruments that the active legitimized subjects dispose to request the sanction of an illicit union and the ineffectiveness of his effects. And the quarter is to determine the sanction that corresponds to apply to the employees involved in the constitution of an illicit union.
\end{abstract}

\section{PALABRAS CLAVE}

Sindicatos ilícitos, Legitimación, Competencia, Sanción trabajadores

\footnotetext{
* Instructor de Derecho del Trabajo y de la Seguridad Social, Facultad de Derecho, Universidad de Chile, Santiago, Chile. Magíster en Derecho del Trabajo y de la Seguridad Social (impartido en conjunto por la Universidad de Talca y la Universidad de Valencia, 2013). Correo electrónico rfernandez@ derecho.uchile.cl.
} 


\section{KEYWORDS}

Illicit unions, Legitimization, Competence, Sanction employees

\section{Introducción}

En el ordenamiento jurídico nacional, no obstante la amplia discrecionalidad de que gozan los trabajadores para constituir los sindicatos que estimen convenientes para sus intereses, éstos necesariamente deben ser constituidos para lograr los fines que les son propios, fines que si bien están enumerados en términos amplios por la normativa nacional, especialmente en el artículo 220 del Código del Trabajo, todos son concreción del objetivo esencial que debe perseguir el sindicato, cual es la promoción y defensa de los intereses profesionales y económicos de los trabajadores vinculados a su calidad de trabajador. Este objetivo constituye la causa nuclear e imprescindible de creación de un sindicato y, a la vez, la finalidad que debe perseguir durante su existencia en la vida del derecho. La actividad de defensa y promoción de los intereses de los trabajadores debe estar en el inconsciente de quienes participan en el acto colectivo y asociativo de creación de un sindicato, constituyendo un elemento de la esencia del mismo', denominado ánimo colectivo o animus sindicali, que tiene una trascendencia equivalente al animus societatis que se exige en el contrato de sociedad regulado por la legislación mercanti ${ }^{2}$.

Si bien en la vida diaria las personas obran de buena fe, la que se presume en el derecho nacional (artículos 707 y 1459 del Código Civil) ${ }^{3}$ y, por tanto, se subentiende que, en la generalidad de los casos, los sindicatos se constituyen para lograr los fines que les son propios, siendo, en efecto, su constitución

\footnotetext{
1 El profesor Macchiavello señala al respecto: "Para nosotros un sindicato requiere poseer los siguientes elementos fundamentales que lo conceptúan: (... 3) tener fines de defensa profesional y de promoción de las calidades morales, intelectuales, físicas y económico-sociales de los trabajadores y de sus familias", MACCHIAVELLO (1989), p. 303. En la doctrina comparada véase especialmente sobre los fines del sindicato FerNÁNDEZ (1982), pp. 36-44; BAYLos (2012), pp. 15-21. El profesor Baylos señala al respecto: "El sindicato tiene como objetivo fundacional y como razón de ser defender a los trabajadores asociados o afiliados al mismo (...). Sabemos que el sindicato se basa en la unión de los trabajadores para la mejora de sus condiciones de trabajo y de empleo y que para ello utiliza medios atípicos de tutela del interés del grupo: la negociación colectiva y la huelga". BAylos (2012), p. 17.

2 Séptimo Juzgado Laboral de Santiago, rol № 2893-2006, 28 de noviembre de 2008; Corte de Apelaciones de Santiago, rol № 8465-2008, 30 de julio de 2009; Corte de Apelaciones de Santiago, rol № 9279-2008, 5 de octubre de 2009. Estas dos últimas sentencias establecen: "el sindicato es comúnmente definido como una asociación de trabajadores que busca el progreso económico y social de sus miembros, especialmente para el mantenimiento y mejora de las condiciones de trabajo a través de una contratación colectiva. El sindicato tiene así una gran semejanza con el contrato de sociedad, incluyendo un animus especial llamado en la sociedad affectio societatis, un animus colectivo".

${ }^{3}$ Disposiciones aplicables al Derecho del Trabajo en virtud de la aplicación supletoria del Código Civil reconocida en el artículo $4^{\circ}$ del Código Civil.
} 
lícita, al perseguir objetivos admitidos, reconocidos, promovidos y protegidos por el ordenamiento jurídico, existe también la posibilidad que se constituyan con fines diversos, esto es, con fines totalmente ajenos a los que les son propios. Esto ocurrirá cuando en la constitución del sindicato se cumplan todos los requisitos formales establecidos en el Código del Trabajo, pero sus fines no sean sindicales, ya que no ha sido constituido con el propósito de defender los derechos e intereses de los trabajadores afiliados. Se trata de sindicatos formados al amparo de las normas legales que regulan el derecho de constituir organizaciones sindicales, siendo los mismos prima facie admitidos, pero se vulnera el espíritu y sentido de tales normas como también los valores y principios contemplados en normas legales de naturaleza imperativa. Son los sindicatos constituidos con abuso del derecho o en fraude a la ley ${ }^{4}$, los cuales si bien no han sido regulados por el legislador laboral y, menos su sanción, su existencia y castigo ha sido reconocida, fundándose en principios jurídicos que rigen en el Derecho del Trabajo, especialmente la libertad sindical ${ }^{5}$, la buena $\mathrm{fe}^{6}$ y la primacía de la realidad ${ }^{7}$, por estimarse que aquellos son un atentado a estos principios que imperan en el Derecho del Trabajo.

Nuestros Tribunales de Justicia han tenido la oportunidad de conocer juicios en que se ha discutido el fin que persigue la constitución del sindicato, habiéndose determinado en ciertas oportunidades que ha sido constituido con abuso del derecho o al menos en fraude a la ley ${ }^{8}$, siendo el caso más emblemático, pero no exclusivo, el denominado por la doctrina ${ }^{9}$ y la jurisprudencia" ${ }^{10}$ "sin-

\footnotetext{
${ }^{4}$ En adelante los términos sindicato ilícito, sindicato con fines ilícitos, sindicato espurio y sindicato con fines instrumentales se emplearán indistintamente para referirse a los sindicatos constituidos con abuso del derecho y en fraude a la ley.

${ }^{5}$ Primer Juzgado de Letras del Trabajo de Santiago, RIT S-44-2010, 9 de noviembre de 2010; Segundo Juzgado de Letras del Trabajo de Santiago, RIT S-50-2010, 30 de diciembre de 2010.

${ }^{6}$ Séptimo Juzgado Laboral de Santiago, rol L-2893-2006, 28 de noviembre de 2008; Corte de Apelaciones de Santiago, rol No 8465-2009, 30 de julio de 2009.

7 Corte de Apelaciones de Santiago, rol No 8465-2009, 30 de julio de 2009; Corte de Apelaciones de Santiago, rol No 2407-2010, 12 de enero de 2011; Corte de Apelaciones de Santiago, rol № 755-2011, 19 de enero de 2012.

${ }^{8}$ En este sentido: Séptimo Juzgado Laboral de Santiago, rol L-2893-2006, 28 de noviembre de 2008; Octavo Juzgado Laboral de Santiago, rol L-74-2007, 16 de junio de 2009; Segundo Juzgado de Letras del Trabajo de Santiago, RIT S-56-2011, 18 de noviembre de 2011; Primer Juzgado de Letras del Trabajo de Santiago, RIT S-106-2011, 23 de marzo de 2012; Segundo Juzgado de Letras del Trabajo de Santiago, RIT I-292-2011, 26 de enero de 2012; Segundo Juzgado de Letras del Trabajo de Santiago, RIT I-305-2011, 16 de febrero de 2012.

${ }^{9}$ Gamonal (2011), p. 460.

${ }^{10}$ Juzgado de Letras del Trabajo de Valdivia, RIT T-21-2009, 9 de marzo de 2010; Corte de Apelaciones de Santiago, rol № 755-2011, 19 de enero de 2012.
} 
dicato del día después"11, que constituye un supuesto de fraude a la ley ${ }^{12}$. La característica esencial para determinar la existencia de un sindicato ilícito es la ausencia de vida sindical y las circunstancias en que se constituye, todo lo cual revela que carecen de animus sindicali ${ }^{13}$. Debido a la ausencia de consagración normativa, no existe uniformidad en su sanción, habiéndose concluido en la mayoría de veces que es la inoponibilidad del acto de constitución sindical y de los efectos derivados del mismo, especialmente del fuero sindical ${ }^{14}$, aunque aisladamente se han sancionado con la nulidad absoluta prevista en el Código Civil, por estimarse que adolecen del vicio de objeto y causa ilícita ${ }^{15}$.

Si bien existe controversia sobre los tipos de sindicatos ilícitos que pueden constituirse y la sanción de los mismos, ello ya ha sido tratado por la doctrina

11 La doctrina nacional sostiene que el sindicato del día después "es aquel en que se constituye una organización sindical luego de despedido uno o varios trabajadores con todas las formalidades legales, dentro de los diez días siguientes al despido, cumpliendo con todas las exigencias formales, con el sólo propósito de dejar sin efecto el despido, ya que estarían amparados los trabajadores constituyentes por el fuero laboral retroactivo de 10 días que consagra el artículo 221 del Código del Trabajo al momento del despido. Y como el empleador no solicitó autorización judicial al despedir a los trabajadores constituyentes de la organización sindical, ni estuvo en condiciones de hacerlo, al no estar en conocimiento del fuero sindical ni de la futura constitución de un sindicato, decisión que, por lo demás, se adopta luego de materializado el despido, en principio el mismo es nulo. Sin embargo, si se descubre cual fue realmente el propósito de la constitución de tal sindicato, el cual quedará de manifiesto con la nula actividad sindical que realiza y las circunstancias en que se constituyó, se determinará que sólo se está ante un sindicato aparente que no es tal, porque carece de ánimo colectivo, habiéndose solamente instrumentalizado las normas que regulan la constitución de organizaciones sindicales, sus derechos y prerrogativas (fuero sindical), con el único propósito de dejar sin efectivo el despido, lograr la reincorporación y estabilidad en el empleo, ya que los trabajadores despedidos no sólo son los que promueven la constitución del sindicato fraudulento, sino que también frecuentemente son elegidos directores sindicales, entrabando el poder de dirección y/o disciplinario del empleador. Tales sindicatos espurios han sido denominados en la doctrina nacional y jurisprudencia judicial como 'sindicatos del día después'. Constituyen el único supuesto de sindicato constituido en fraude a la ley de que han conocido nuestros Tribunales de Justicia". FERNÁNDEZ (2014 a), pp. 285.

12 Véase sobre el problema de calificación de los sindicatos del día después Fernández (2014 a), pp. 284-291.

13 Véase Fernández (2014 a), pp. 265-314.

${ }^{14}$ En este sentido Séptimo Juzgado Laboral de Santiago, rol L-2893-2006, 28 de noviembre de 2008; Octavo Juzgado Laboral de Santiago, rol No L-74-2007, 16 de junio de 2009; Cuarto Juzgado Laboral de Santiago, rol No L-2803-2006, de 26 de diciembre de 2008; Corte de Apelaciones de Santiago, rol $\mathrm{N}^{\circ}$ 8465-2009, 30 de julio de 2009; Corte de Apelaciones de Santiago, rol № 2407-2010, 12 de enero de 2011; Segundo Juzgado de Letras del Trabajo de Santiago, RIT № S-56-2011, 18 de noviembre de 2011; Primer Juzgado de Letras de Santiago, RIT S-106-2011, 23 de marzo de 2012.

15 Juzgado de Letras del Trabajo de Valdivia, RIT O-117-2010, 13 de noviembre de 2010; Corte de Apelaciones de Valdivia, Rol Reforma Laboral № 213-2010, 5 de enero de 2011. 
nacional, sea detalladamente ${ }^{16} \mathrm{o}$ en forma somera ${ }^{17}$. Pero no ocurre lo mismo con otros aspectos de la constitución de sindicatos con abuso del derecho y en fraude a la ley, que no han sido tratados por la doctrina y respecto de los cuales existe un estado de confusión en la jurisprudencia, por lo que estos aspectos serán el objeto del presente trabajo, y se exponen a continuación.

Es así que la competencia para conocer de los conflictos y reclamos en que se discute la existencia de sindicatos espurios es de los Tribunales de Justicia, al requerirse de un juicio contradictorio, de lato conocimiento, y necesitarse de pruebas que acrediten las circunstancias fácticas constitutivas de tales sindicatos. Sin embargo, surge la duda de cuáles son los tribunales competentes, confusión que se debe a que las normas sobre competencia absoluta contenidas en el artículo 420 del Código del Trabajo están redactadas en forma ambigua y confusa. Es por ello que los Tribunales de Justicia se han pronunciado en forma contradictoria, existiendo sentencias que sostienen que los tribunales competentes son los Juzgados Civiles, y otras que concluyen que la competencia para conocer controversias de esta naturaleza son los Juzgados de Letras con competencia en materia laboral. Asimismo, corresponde determinar si la Inspección del Trabajo tiene también competencia para conocer de las controversias señaladas.

Discutida es también en la jurisprudencia judicial la legitimación activa del empleador para cuestionar y solicitar la sanción de los sindicatos ilícitos o bien la ineficacia de sus efectos. Algunas sentencias judiciales niegan la legitimación activa al empleador, fundado en una interpretación exegética de las normas legales existentes, confiriéndosela solamente a los trabajadores y a la Inspección del Trabajo. Pero también existe otra tendencia jurisprudencial que admite que el empleador haga valer acciones y excepciones fundado en la constitución de sindicatos ilícitos, no viendo inconvenientes en ello.

Asimismo, no existe claridad sobre cuáles son los instrumentos de que disponen los legitimados activos para solicitar la sanción de los sindicatos constituidos con fines ilícitos y la ineficacia de sus efectos, siendo necesario determinarlos.

Por otro lado, debido a que es posible que los trabajadores constituyan sindicatos con propósitos ilícitos vigente el contrato individual de trabajo, establecida y declarada tal situación del sindicato, el empleador puede ejercer su poder disciplinario, debiéndose determinar cuál es la sanción que puede aplicar al trabajador que ha intervenido en la constitución de tales sindicatos, que incluso se pudo beneficiar de las prerrogativas y derechos que derivan del

\footnotetext{
${ }^{16}$ Véase sobre la configuración jurídica de los sindicatos constituidos con abuso del derecho y en fraude a la ley y las consecuencias jurídicas que derivan de los mismos en el Ordenamiento Jurídico chileno Fernández (2014 a), pp. 265-314.

17 Gamonal (2011), pp. 460-461; Toledo (2013), pp. 95, 201-205; Olavarría (2013), pp. 503-511.
} 
mismo. Para ello se debe recurrir a las normas generales que regulan las sanciones que puede aplicar el empleador.

Como se puede observar, existe una variedad de posiciones sobre cada uno de los cuatro aspectos señalados de los sindicatos constituidos con fines no sindicales, lo que se debe principalmente a la ausencia de disposiciones legales que los regulen y a la interpretación contradictoria de las normas existentes. Es por ello que en este trabajo se pretende responder a las siguientes preguntas: ¿cuál es el órgano del Estado competente para conocer de las contiendas en que se discute la existencia de sindicatos con fines ilícitos y determinar la sanción a aplicar a los mismos? ¿Quiénes son los legitimados activos para denunciar la constitución de un sindicato ilícito y solicitar su sanción? ¿Quiénes pueden ser legitimados pasivos?; ¿De qué instrumentos disponen los legitimados activos para solicitar la sanción de un sindicato ilícito e ineficacia de sus efectos?; ¿a través de qué procedimiento se tramitan los juicios en que se discute la existencia de un sindicato ilícito? y ¿Cuál es la sanción que corresponde aplicar a los trabajadores dependientes que participan en su constitución?

Para lograr los objetivos propuestos se recurrió a fuentes normativas y bibliográficas $^{18}$. También se acudió a la jurisprudencia judicial ${ }^{19}$ y administrativa ${ }^{20}$, que si bien no es fuente formal del derecho en nuestro ordenamiento jurídico, tiene trascendencia, especialmente en la constitución de sindicatos con fines

18 Especialmente las investigaciones que los autores nacionales han realizado sobre derecho sindical, sea en monografías, obras de derecho colectivo, como también artículos publicados en revistas especializadas. También se acudió a los estudios sobre derecho procesal civil en que se trata la acción, excepción y legitimación. Por su parte, la doctrina extranjera se utilizó solamente como argumento de refuerzo, acudiendo principalmente a estudios de derecho procesal

19 Se ha considerado como universo de estudio las sentencias de los Tribunales de Justicia, es decir, de los Juzgados del Trabajo y de los Juzgados Civiles con competencia en lo laboral, de las Cortes de Apelaciones del país y de la Excelentísima Corte Suprema, que hayan sido publicadas a partir del año 1990 en las revistas especializadas a saber: Revista de Derecho y Jurisprudencia, Revista Fallos del Mes, Gaceta Jurídica y Revista Laboral Chilena. A este universo de estudio se plantean tres excepciones. Primero, debido a que no todas las sentencias de la Excelentísima Corte Suprema se publican en revistas especializadas, las sentencias dictadas por la Cuarta Sala de la Excelentísima Corte Suprema a partir del 1 de enero de 2007 se han publicado en la página web del Poder Judicial, por lo que su revisión también se ha efectuado a través de dicha página web. En segundo lugar, la revisión de las sentencias judiciales pronunciadas por los tribunales del país indicados desde el año 2000 se ha efectuado, igualmente, a través de los buscadores electrónicos Microjuris, JurisChile y LegalPublishing. Y tercero, se consideraron sentencias judiciales cuyo conocimiento se ha obtenido de colegas como consecuencia del ejercicio de la profesión, siendo ésta la principal fuente de conocimiento de la jurisprudencia que se utilizó.

${ }^{20}$ Se consideran los dictámenes emanados de la Dirección del Trabajo desde el año 1993 pronunciados sobre los sindicatos constituidos con abuso del derecho y fraude a la ley, como también sobre permisos sindicales y fuero sindical, publicados en la página web de la Dirección del Trabajo. 
ilícitos, al ser la que se ha pronunciado sobre distintos aspectos de los mismos y por no existir norma legal al respecto.

\section{2. Órgano competente para sancionar los sindicatos constituidos con fines ilícitos}

Es claro que el empleador de propia iniciativa no puede calificar por sí mismo un sindicato como constituido con abuso del derecho o en fraude a la ley, y sancionar dichas organizaciones sindicales mediante el desconocimiento de facto de su existencia y de los efectos jurídicos que derivan del acto de constitución sindical, como lo son el fuero sindical y los permisos sindicales. De hacerlo, incurre el empleador en un acto de autotutela no permitido por la legislación laboral nacional ${ }^{21}$, debiendo ser sancionando por dicha conducta, la que generalmente se hará mediante una condena por práctica antisindical ${ }^{22} \mathrm{y} / \mathrm{o}$ multa, al desconocer de hecho un sindicato que tiene apariencia de legalidad

${ }^{21}$ El Cuarto Juzgado de Letras de Copiapó ha resuelto: "Al empleador no le corresponde analizar o no la legalidad de la constitución de un sindicato, puesto que ese ha sido el argumento señalado por el denunciado para explicar la negativa y demora en reincorporar al trabajador a sus labores, puesto que para ello existe un procedimiento especial en material laboral" (Cuarto Juzgado de Letras de Copiapó, rol № 368-2007, 3 de julio de 2007). En términos similares el Octavo Juzgado del Trabajo de Santiago ha fallado: "Ignorar la existencia del sindicato so pretexto de las supuestas irregularidades que se advierten en su constitución, desconociendo la legalidad de tal órgano, expresamente avalada por la Inspección del Trabajo, constituye un acto de autotutela, especialmente si tal actitud es seguida de la renuencia a reincorporar a trabajadores que se encontraban en la situación descrita en el artículo 224 del Código del Trabajo" (Octavo Juzgado del Trabajo de Santiago, rol № 4374-2003, 15 de junio de 2004). Por su parte, el Juzgado de Letras del Trabajo de San Miguel ha sostenido: "DECIMO QUINTO: Que evidencia el ánimo atentatorio contra la libertad sindical por parte del empleador su actitud contumaz en el cumplimiento de las órdenes administrativas, ya que puesto en su conocimiento por la institución respectiva de la obligación de reincorporar a trabajadores aforados, se negó a ello, alegando que tenía su dotación completa.

DECIMO SEXTO: Que lo anterior evidencia una acción positiva por parte del empleador de hacer justicia por sus propias manos, atribuyéndose facultades que le están entregadas en primer término a una institución estatal y en segundo término a los tribunales laborales, encargados de resolver conflictos de este tipo, no pudiendo los particulares atribuirse la facultad de decidir por sí y ante sí que el fuero sindical no impide un despido y por ellos negarse a cumplir con un requerimiento de la autoridad, hecho que a juicio de esta sentenciadora atenta contra la libertad sindical, ya que la consecuencia de la actividad desplegada por la empleadora impide la comunicación de la directiva del sindicato con los asociados que trabajan en el colegio Esgelavi, que según el decir del Sr. Olave son alrededor de cuatro" (Juzgado de Letras del Trabajo de San Miguel, RIT S-3-2011, 17 de agosto de 2011). En similares términos: Tercer Juzgado del Trabajo de Santiago, rol No 4025-2003, 6 de abril de 2006; Quinto Juzgado del Trabajo de Santiago, rol № 2374-2006, 5 de abril de 2007; Juzgado de Letras del Trabajo de Antofagasta, RIT S-3-2009, 26 de octubre de 2009; Corte de Apelaciones de Santiago, Rol Reforma Laboral No 107-2010, 16 de abril de 2010; Corte de Apelaciones de Antofagasta, Rol Reforma Laboral № 17-2014, 13 de mayo de 2014.

${ }^{22}$ Quinto Juzgado del Trabajo de Santiago, rol № 2374-2006, 5 de abril de 2007; Juzgado de Letras del Trabajo de Antofagasta, RIT S-3-2009, 26 de octubre de 2009; Segundo Juzgado de Letras del Trabajo 
refrendada por la actuación de la Inspección del Trabajo -la que no formula observaciones al sindicato en la etapa de control del acto de constitución-, sin recurrir previamente al órgano competente a través de los instrumentos que el legislador pone a su disposición para obtener la sanción de los sindicatos ilícitos.

La autotutela ha sido prácticamente desterrada de los Estados Democráticos de Derecho, quedando restringida para ciertos casos, enumerados, eso sí, expresamente por el legislador, no pudiendo extenderse más allá de los supuestos en que el legislador la ha admitido. El Estado ha asumido la función de interpretar y aplicar correctamente las normas jurídicas, sancionando las conductas que atentan contra alguna disposición jurídica, y reestablecer el imperio del derecho cuando ha sido conculcado. Sin embargo, como se está en el campo del derecho público, donde solamente se puede hacer aquello que permite el ordenamiento jurídico, tal como lo ordena el principio de juridicidad consagrado en los artículos $6^{\circ}$ y $7^{\circ}$ de la Constitución Política, corresponde determinar cuál es el órgano del Estado que tiene la función de conocer de los reclamos y juicios donde se denuncia la existencia de sindicatos constituidos con abuso del derecho o en fraude a la ley, y sancionarlos cuando sea efectivo que se constituyeron con algunas de las anormalidades señaladas, por constituir verdaderos ilícitos laborales.

Debido a la pluralidad de órganos del Estado que tienen competencia para conocer de las controversias en que se invocan las normas y principios vulnerados con la constitución de sindicatos con fines ilícitos, corresponde determinar cuál es el órgano competente para conocer de estas contiendas. Precisar esto no es irrelevante, debido a que si se solicita a un órgano incompetente el conocimiento de la controversia, el mismo se deberá declarar incompetente, en este caso, absolutamente en razón de la materia, no pudiendo abocarse a conocer contiendas que el legislador no le ha encomendado. De ahí que sea necesario y conveniente solicitar el conocimiento de la contienda al órgano competente.

\subsection{Incompetencia absoluta de la Inspección del Trabajo para sancionar los sindicatos ilícitos}

La Inspección del Trabajo no es el órgano competente para conocer de reclamos o denuncias sobre organizaciones sindicales constituidas con abuso del derecho o en fraude a la ley, por no haberle concedido la ley competencia para ello, ni ninguna otra norma jurídica. Dicha conclusión que se ve reafirmada con la constatación que el legislador laboral no reguló el abuso del derecho y el fraude a la ley de modo general, y menos contempló los sindicatos constituidos con abuso del derecho y en fraude a la ley como tampoco las consecuencias

de Santiago, RIT T-43-2009, 11 de enero de 2010; Corte de Apelaciones de Santiago, 16 de abril de 2010, Rol Reforma Laboral № 107-2010. 
jurídicas que derivan de los mismos. Su sanción se ha fundado en los principios jurídicos de la libertad sindical, la primacía de la realidad y la buena fe.

La Inspección del Trabajo solamente tiene competencia para fiscalizar los requisitos formales de constitución de los sindicatos en la forma dispuesta por el artículo 223 del Código del Trabajo, bastando para ello examinar el acta de constitución y los estatutos sindicales, determinando si en los mismos se cumplen o no tales exigencias. Sin embargo, no ocurre lo mismo con los requisitos de fondo del sindicato, constituido por el ánimo colectivo denominado también animus sindicali, esto es, la intención de los trabajadores de constituir un sindicato para lograr los fines que le son propios, elemento de carácter subjetivo cuya constatación, de ser controvertida, requiere de un procedimiento contradictorio de lato conocimiento, donde pueda ofrecerse y rendirse prueba por las partes, el que solamente puede desarrollarse ante los Tribunales de Justicia como regla general. De esta forma, la Inspección del Trabajo es incompetente absolutamente para conocer de denuncias o reclamos sobre sindicatos constituidos con fines ilícitos. De ahí que si algún sujeto del derecho del trabajo interpone una denuncia o reclamo ante la Inspección del Trabajo solicitando la sanción de un sindicato constituido con abuso del derecho o en fraude a la ley, esta debe declararse incompetente de oficio, pues no puede atribuirse facultades ni funciones que no le han sido otorgadas por norma jurídica alguna. Esta conclusión encuentra su sustento en el principio de juridicidad, cuyo fundamento directo está en la Constitución Política, especialmente en sus artículos $6^{\circ}$ y $7^{\circ}$.

Ahora bien, si solicitada la intervención de la Inspección del Trabajo sanciona un sindicato constituido con fines ilícitos, no declarándose incompetente, la resolución que dicta es ilegal, siendo susceptible de ser impugnada ante los Tribunales de Justicia competentes.

\subsection{Competencia de los Tribunales de Justicia. Determinación del Tribunal de Justicia competente}

Dilucidado lo anterior, no queda más que concluir que son los Tribunales de Justicia los competentes para conocer de los conflictos que se originan con motivo de la constitución de sindicatos con fines ilícitos. La misma Dirección del Trabajo confirma esta conclusión, al sostener que de constituirse un sindicato del día después -que es un supuesto de sindicato constituido en fraude a la ley-con el solo propósito de beneficiarse los trabajadores del fuero sindical que nace con el acto de constitución del sindicato, tal situación deberá "ponerse en conocimiento de los Tribunales de Justicia a fin de que sea esta instancia jurisdiccional la que se pronuncie al respecto" ${ }^{\prime 23}$.

${ }^{23}$ Dictamen Dirección del Trabajo, № 5357/245, 12 de diciembre de 2003. 
Si se considera que en los sindicatos constituidos con abuso del derecho y en fraude a la ley se cumplen las exigencias formales que establece el legislador, los mismos gozan de una presunción de legalidad, al menos aparente, ratificada por la Inspección del Trabajo al no formular observaciones al acto de constitución sindical e inscribirlos en el registro de sindicatos, siendo necesario para destruir tal apariencia comprobar la desviación de la finalidad legítima de las normas que regulan los sindicatos y la ausencia del animus sindicali, lo que debe ser declarado judicialmente. Sólo la fuerza coactiva y declarativa que proviene de una sentencia pronunciada por los Tribunales de Justicia puede romper la apariencia de legalidad que existe en un sindicato ilícito, restableciendo el imperio del derecho ${ }^{24}$. La declaración judicial pone de manifiesto la ilicitud del sindicato siendo el instrumento idóneo para imponer la sanción correspondiente, que no opera de pleno derecho. Si no hay declaración judicial que sancione el sindicato cuestionado como ilícito, el mismo produce plenos efectos jurídicos, gozando de todos los derechos, prerrogativas e instrumentos de protección que el ordenamiento laboral establece para los sindicatos.

La debida aplicación de las normas defraudadas con los sindicatos constituidos con abuso del derecho y en fraude a la ley hace necesaria la correcta interpretación y aplicación de las mismas por el juez. Será éste quien determine la debida y correcta aplicación de las normas en juego, declarando mediante sentencia definitiva cuándo un sindicato fue constituido con fines ilícitos y aplicar la sanción que sea procedente.

Si bien parece existir claridad sobre la competencia de los Tribunales de Justicia para conocer de los juicios en que se discute la existencia de un sindicato constituido con fines ilícitos, persiste la duda sobre si los tribunales competentes son los Juzgados de Letras del Trabajo o bien los Tribunales de Justicia con competencia común, cuales son los Juzgados de Letras Civiles, debido a que las normas legales que regulan la competencia de los Juzgados de Letras del Trabajo sobre organizaciones sindicales no son del todo claras, lo que ha provocado que existan pronunciamientos judiciales contradictorios.

i) Competencia de los Juzgados de Letras Civiles. Un sector de la jurisprudencia $^{25}$ sostiene que los Juzgados de Letras del Trabajo son incompetentes absolutamente para conocer de la impugnación de las organizaciones sindicales por falta de requisitos sustanciales, especialmente, cuando se solicita su inexis-

${ }^{24}$ Véase Sols (1989), pp. 241-247.

25 Corte Suprema, rol № 365-2008, 8 de abril de 2008; Corte Suprema, rol № 368-2008, 8 de abril de 2008; Juzgado de Letras del Trabajo de Antofagasta, RIT S-3-2009, 13 de noviembre de 2009; Juzgado de Letras del Trabajo de Antofagasta, RIT S-4-2009, 26 de noviembre de 2009; Corte de Apelaciones de Talca, Rol Reforma Laboral № 87-2011, 29 de septiembre de 2011; Segundo Juzgado de Letras del Trabajo de Santiago, RIT O-2623-2011, 21 de octubre de 2011. 
tencia o nulidad absoluta. Esta posición se funda, principalmente, en el tenor literal del artículo 420 letra b) del Código del Trabajo, el cual dispone: "Serán de competencia de los Juzgados de Letras del Trabajo: b) las cuestiones derivadas de la aplicación de las normas sobre organización sindical (...) que la ley entrega al conocimiento de los juzgados de letras con competencia en materia laboral". De acuerdo a las expresiones utilizadas por el artículo transcrito -según esta posición- para que un tribunal laboral posea la facultad de conocer de los conflictos relativos a las organizaciones sindicales es necesario que dicho conocimiento le sea concedido expresamente por la ley, y en el evento que el legislador no haga esa concesión, la competencia no existe, como ocurre, precisamente, con las controversias sobre los sindicatos constituidos con fines ilícitos, en que no existe ninguna norma legal que otorgue competencia para conocer de estas materias a los tribunales con competencia laboral. Los únicos preceptos legales que otorgan competencia a los Juzgados de Letras del Trabajo para conocer de controversias sobre organizaciones sindicales son los artículos 223 y 297 del Código del Trabajo. El primero sólo respecto de reclamaciones que formule el propio sindicato a propósito del ejercicio de la facultad que tiene la Inspección del Trabajo para observar defectos en la constitución del mismo, entre los que no se encuentran los defectos en los requisitos internos del sindicato, como lo es el ánimo colectivo, sino sólo los requisitos formales. Por su parte, el artículo 297 del Código del Trabajo otorga competencia a los Tribunales del Trabajo para conocer de las solicitudes de disolución de las organizaciones sindicales que formulen los trabajadores afiliados al sindicato respectivo o la Inspección del Trabajo.

Se agrega que la circunstancia que se requiera de la expresa mención de la ley sobre las materias relacionadas con la organización sindical susceptibles de intervención jurisdiccional especial, resulta coherente con la mayor autonomía sindical pretendida a través de las modificaciones introducidas al Código del Trabajo por la ley No 19.759, sin que ello lleve a determinar que no sea posible someter ante tribunal alguno de la República un juicio en donde se discuta acerca de los sindicatos ilícitos ${ }^{26}$. Esta conclusión resultaría acorde con las normas generales de competencia contenidas en el Código Orgánico de Tribunales, especialmente con lo dispuesto por su artículo 108, que define la competencia como la facultad que tiene cada juez o tribunal para conocer de los negocios que la ley ha colocado dentro de la esfera de sus atribuciones. Y como en materia laboral no existe prórroga de competencia (artículo 423 inciso $2^{\circ}$ del Código del Trabajo), sólo la ley determina cuándo los Juzgados de Letras

${ }^{26}$ Corte Suprema, rol № 365-2008, 8 de abril de 2008; Corte Suprema, rol № 368-2008, 8 de abril de 2008; Corte de Apelaciones de Talca, Rol Reforma Laboral № 87-2011, 29 de septiembre de 2011. 
del Trabajo tienen competencia para conocer asuntos labores. De no existir -lo que precisamente ocurriría en la materia objeto de nuestro estudio- los Juzgados de Letras del Trabajo son incompetentes absolutamente.

De acuerdo a esta posición, los tribunales competentes para conocer de los juicios sobre los sindicatos constituidos con fines ilícitos son los Juzgados de Letras en lo Civil, ya que son los tribunales con competencia común, que conocen las materias que no han sido encomendadas a los tribunales con competencia especializada, carácter que tienen los Juzgados de Letras del Trabajo, conclusión esta última que se desprende de las sentencias judiciales que siguen esta posición, pues no lo señalan expresamente sino que lo dejan entrever.

ii) Competencia de los Juzgados de Letras del Trabajo. Existe una segunda posición jurisprudencial que sostiene que son los Juzgados de Letras del Trabajo los tribunales que tienen competencia para conocer de los juicios en que se discute si un sindicato ha sido constituido con fines ilícitos, principalmente, cuando se solicita su inoponibilidad fundado en que se ha constituido en fraude a la ley o bien con abuso del derecho. Así, en todos los casos en que se ha declarado la ineficacia de los efectos de un sindicato en fraude a la ley o con abuso del derecho -principalmente del fuero sindical- han sido los Juzgados de Letras con competencia laboral quienes han conocido de esos juicios, no habiéndose declarado incompetentes. Lo mismo ocurrió con el único caso existente en nuestro país en que se declaró la nulidad absoluta de un "sindicato del día después", que fue conocido por el Juzgado de Letras del Trabajo de Valdivia, donde se rechazó la excepción de incompetencia absoluta opuesta por el sindicato demandado ${ }^{27}$.

Esta posición no le da una interpretación estrictamente literal al artículo 420 letra b) del Código del Trabajo y se funda, además, en la letra a) del mismo artículo, conforme al cual los Juzgados de Letras con competencia laboral pueden conocer de las contiendas donde se discute el sentido y alcance de las normas laborales, no exigiendo que una norma legal expresa les confiera competencia.

Controvertida resulta ser la conclusión sostenida por algunos Tribunales de Justicia nacionales en orden a que los Juzgados Civiles son quienes tienen competencia para conocer los juicios en que se discute la validez de un sindicato, debido a que existen numerosos argumentos que la desvirtúan. En primer lugar, el alcance que se le atribuye a la letra b) del artículo 420 del Código del Trabajo no es tal. Ello porque el énfasis no debe ponerse en la exigencia que la ley expresamente debe otorgar competencia a los Juzgados de Letras del Traba-

\footnotetext{
27 Juzgado de Letras del Trabajo de Valdivia, RIT O-117-2010, 13 de noviembre de 2010. En similares términos Juzgado de Letras del Trabajo de San Miguel, RIT O-45-2013, 30 de mayo de 2013.
} 
jo para conocer sobre controversias acerca de organizaciones sindicales, sino en que lo discutido sean materias sindicales, carácter que sin duda tienen los juicios en que se discute la sanción aplicable a los sindicatos constituidos con fines ilícitos y/o a los efectos que se originan con su constitución. Los Juzgados de Letras con competencia laboral son los Tribunales de Justicia por excelencia para conocer de las contiendas sobre sindicatos ilícitos, al tener la experiencia y conocimiento de las normas laborales más que ningún otro Tribunal de Justicia. Resulta absurdo e ilógico que Tribunales de Justicia que no tienen experiencia y el conocimiento adecuado para conocer de juicios en que se discuta el sentido y alcance de normas laborales, conozcan de controversias en que se cuestiona la existencia de los sindicatos constituidos en fraude a la ley o con abuso del derecho. Por lo mismo, es perfectamente posible sostener que el artículo 420 letra b) confiere una competencia genérica en materias sindicales a los Juzgados de Letras del Trabajo, ya que de concluir lo contrario no se entenderían los razones del establecimiento de este precepto, que sería abiertamente redundante con aquellas normas especiales contenidas en el Código del Trabajo que otorgan competencia en materias sindicales a los Juzgados de Letras del Trabajo, pues, si no existiera dicha norma, de todas formas el legislador podría otorgar expresamente competencia al juez laboral sobre cuestiones sindicales, de ahí que carece de fundamento razonable la interpretación que le da la posición jurisprudencial expuesta en la letra i) al artículo 420 letra b) del Código del Trabajo.

A mayor abundamiento, la letra g) del artículo 420 del Código del Trabajo contempla expresamente la competencia de los Juzgados de Letras del Trabajo en aquellas materias que las leyes entreguen a juzgados de letras con competencia laboral, por lo que tampoco se entendería la inclusión particular de la letra b), de atribuirle una interpretación literal ${ }^{28}$, pues sería redundante y bastaría con la letra g) del artículo 420 del Código del Trabajo, pues a las normas sobre competencia absoluta de los Juzgados de Letras del Trabajo debe darse una interpretación coherente con el resto del ordenamiento jurídico, procurando que puedan tener una aplicación efectiva. Así, entonces, se concluye que los Juzgados de Letras del Trabajo son competentes para conocer de todas las cuestiones derivadas de la aplicación de las normas sobre organización sindical, sin requerirse una concesión expresa en tal sentido por una norma legal ${ }^{29}$. Por lo demás, no existe Tribunal de Justicia más adecuado para conocer de esta materia que los Juzgados de Letras del Trabajo, que son tribunales especializados que, precisamente, conocen de los juicios en que se discute el sentido y alcance

${ }^{28}$ Lanata (2011), p. 36. En el mismo sentido Corte de Apelaciones de Santiago, rol № 1576-1996, 16 de julio de 1996.

29 Lanata (2011), p. 39. 
de las normas laborales, entre las que se encuentran, evidentemente, las que regulan las organizaciones sindicales.

\section{Legitimación para solicitar la sanción de los sindicatos constituidos con fines ilícitos}

La legitimación ${ }^{30}$ es un presupuesto de eficacia de todo acto jurídico, de ahí que se le haya definido como "el reconocimiento que hace el derecho a una persona de la posibilidad de realizar con eficacia un acto jurídico, derivando dicha posibilidad de una determinada relación existente entre el sujeto y el objeto del mismo" ${ }^{\prime \prime}$.

En lo que dice relación con la legitimación en el proceso judicial, denominada legitimación procesal ${ }^{32}$, constituye un poder que le viene conferido a un sujeto en virtud de una posición jurídica anterior en que se encuentra respecto del objeto litigioso (posición legitimante), y que le faculta para acudir a los Tribunales de Justicia solicitando una resolución judicial respecto del objeto mismo. Si bien resulta controvertida la naturaleza jurídica de la legitimación procesal $^{33}$, sostenemos que en el proceso laboral nacional debe entenderse como la titularidad de la situación jurídica controvertida, constituyendo un presupuesto de fondo de la acción ${ }^{34}$ que permite obtener la tutela efectiva por medio de una sentencia con un contenido concreto ${ }^{35}$.

Según se puede observar, a través de la legitimación procesal se determina quién es el portador legítimo del derecho de acción y contra quién debe dirigirse para el éxito de la misma. Si el que solicita la protección jurídica al órgano jurisdiccional no tiene legitimación activa, o se deduce contra un sujeto que no es legitimado pasivo, esa petición de tutela jurisdiccional no puede prosperar, al faltar un elemento constitutivo de la acción ${ }^{36}$.

\footnotetext{
30 Véase entre otras obras sobre la legitimación VésCOvı (1984), pp. 193-198; MONTERO (2007), pp. 550.

31 Ladaria (1952), p. 11.

32 También se denomina legitimatio ad causam.

${ }^{33}$ Véase un resumen de las distintas posiciones sobre la naturaleza jurídica de la legitimación en MONTERO (2007), pp. 65-82.

34 En este sentido Alsina (1941), pp. 224-225; Calamandrei (1998), pp. 49-55; Romero (2006), pp. 87-88. En sentido contrario se postula que la legitimación procesal es una condición de éxito de la pretensión, la que es defendida por los autores que ven en la acción un derecho procesal público de contenido abstracto dirigido solamente hacia el Estado. En este sentido Devis (1961), pp. 538-540; Devis (1966), pp. 288-290; Guasp y Argoneses (2002), pp. 241-242; Maturana (2006), p. 45.

${ }^{35}$ CORDÓn (1998), p. 372.

${ }^{36}$ Para quienes son partidarios de que la legitimación procesal es una condición del éxito de la pretensión, la misma determina quién es el portador legítimo de la pretensión solicitada en la demanda
} 
La legitimación se dirige a determinar quiénes pueden tener la calidad de justa parte en el proceso. En palabras de Liebman "la legitimación es la titularidad (activa y pasiva) de la acción. El problema de la legitimación consiste en individualizar la persona a la cual le corresponde el interés para accionar ( $y$, por consiguiente, la acción); y la persona frente a la cual el mismo corresponde" ${ }^{\prime 37}$. Como requisito de la acción, es una condición de la providencia de fondo sobre la demanda ${ }^{38}$; indica, pues, para cada proceso, las justas partes, las partes legítimas, esto es, las personas que deben estar presentes a fin que el juez pueda proveer sobre un determinado objeto ${ }^{39}$. De este modo, sin perjuicio de los demás requisitos necesarios para acoger la acción, necesariamente debe concurrir la legitimación activa y pasiva, siendo los primeros elementos que debe determinar el juez de fondo si concurren o no en la acción ejercida al momento de dictar la sentencia definitiva. Si concurren pasará a examinar los demás elementos de la acción. De no concurrir, la acción necesariamente deberá ser rechazada, siendo inoficioso examinar los restantes elementos de la acción ${ }^{40}$.

En conclusión, la legitimación procesal, o legitimación en causa es un presupuesto de fondo y de eficacia jurídica de la acción, básica y esencial para

y contra quién debe dirigirse para el éxito de la misma. Sin perjuicio de esta diferencia dogmática, los efectos procesales que se siguen son los mismos, sea que se estime que la legitimación es condición necesaria para pronunciarse sobre el fondo de la acción o bien sobre el fondo de la pretensión.

37 LieBMAN (1980), p. 116.

38 Señala Chiovenda "para que el juez estime la demanda, no basta que estime existente el derecho, sino se requiere que considere que este corresponde precisamente a aquel que lo hace valer y contra aquel contra quien es hecho valer; o sea, considere la identidad de la persona del actor con la persona en cuyo favor está la ley (legitimación activa) y la identidad de la persona del demandado con la persona contra quien se dirige la voluntad de la ley (legitimación pasiva)", CHIOvendA (2002), p. 108.

39 Chiovenda (2002), p. 117.

${ }^{40}$ La Corte Suprema ha resuelto sobre la legitimación procesal: "QUINTO: Que para poder actuar y figurar eficazmente como parte, en un proceso determinado y específico, no basta con disponer de la aptitud general de la capacidad o legitimatio ad processum, sino que es necesario además poseer una condición más precisa y referida en forma particularizada al proceso individual de que se trate. Tal condición que se denomina legitimatio ad causam o legitimación procesal afecta al proceso no en su dimensión común, sino en lo que tiene de individual y determinado. La legitimación procesal es la consideración especial, que tiene la ley, dentro de cada proceso, a las personas que se hallan en una determinada relación con el objeto litigioso, y en virtud de la cual, exige, para que la pretensión procesal pueda ser examinada en cuanto al fondo, que sean dichas personas las que figuren como parte en el proceso [...].

SEXTO: Que la legitimación procesal es un presupuesto de eficacia para que la sentencia pueda acoger la pretensión que se haya hecho valer por el actor en el proceso, puesto que si ella falta, no podrá existir por parte del tribunal un pronunciamiento sobre el conflicto promovido en el juicio. Al respecto cabe destacar, que reiterada jurisprudencia y la mayoría de la doctrina sobre la materia concuerdan en que la legitimación es un presupuesto procesal de la sentencia, que los propios jueces del fondo pueden relevar de oficio, aunque la parte no haya señalado alegación pertinente al efecto" (Corte Suprema, rol № 5615-2005, 9 de julio de 2007). En igual sentido Corte Suprema, rol № 2032-2008, 1 de julio de 2008. 
acceder a la tutela judicial, tal como lo ha resuelto la Corte Suprema ${ }^{41}$. Las principales situaciones justificantes de la legitimación activa son las fuentes de las obligaciones, los derechos subjetivos y los intereses legítimos ${ }^{42}$.

\subsection{Legitimación activa para solicitar la sanción de los sindicatos ilícitos. Generalidades}

Una de las cuestiones más controvertidas en el ámbito judicial es quién tiene legitimación activa para solicitar la sanción de los sindicatos constituidos con fines ilícitos o bien alegar la ineficacia de los efectos jurídicos que derivan del acto de constitución sindical, especialmente del fuero sindical. Discusión que se ha suscitado a propósito de determinar si el empleador puede ejercer una acción, interponer una excepción o defensa, fundado en la ilicitud del sindicato constituido por trabajadores dependientes de aquel.

Como idea preliminar se puede sostener que tienen legitimación procesal activa para cuestionar la constitución de un sindicato con fines ilícitos y solicitar su sanción, o bien pedir la ineficacia de algunos de los derechos y prerrogativas que derivan de la constitución del mismo, la Inspección del Trabajo, el empleador de los trabajadores constituyentes del sindicato, los trabajadores y otros sindicatos. Sin embargo, atendido que el fundamento jurídico es distinto respecto de cada legitimado activo, como también los problemas particulares que se plantean, es necesario tratar de forma separada su legitimación activa.

\section{a) Legitimación activa de la Inspección del Trabajo}

En nuestra opinión, no cabe duda de que la Inspección del Trabajo puede accionar para que se sancione a un sindicato constituido con abuso del derecho o en fraude a la ley. Sin embargo, esto no lo puede realizar fundado en la disposición del artículo 223 del Código del Trabajo, formulando observaciones al acto de constitución del sindicato para que sean corregidas por los trabajadores constituyentes. Ello fundamentalmente por dos razones. En primer lugar, el contenido de la norma prevista en el artículo 223 es indicativo que la Inspección del Trabajo sólo está facultada para fiscalizar si el sindicato cumple con las exigencias formales de constitución (quórum, presencia ministro fe, depósito acta y estatutos dentro del plazo legal, contenido mínimo estatutos, etc.), lo que puede constatar mediante la revisión de los documentos que la directiva sindical deposita en la Inspección del Trabajo. De entrar a fiscalizar

${ }^{41}$ Corte Suprema, rol № 8824-2011, 12 de julio de 2012; Corte Suprema, rol № 11.031-2011, 16 de agosto de 2012; Corte Suprema, rol № 1839-2012, 19 de diciembre de 2012.

42 Romero (2006), pp. 88-91. 
el cumplimiento de los requisitos de fondo del sindicato, ejercería una función propia de los Tribunales de Justicia que no se le ha encomendado por el legislador, al necesitarse mayores antecedentes para verificar dichos requisitos, corriendo el riesgo de ejercer funciones jurisdiccionales, lo que le está vedado, al menos en esta materia. En segundo lugar, aun cuando tuviera la función de controlar que el sindicato constituido persiga cumplir con los fines que le son propios, se encuentra en la imposibilidad de lograr tal objetivo por no contar con las herramientas necesarias para ello, como son los medios y tiempo para determinar cuáles son los fines que realmente persigue el sindicato constituido, cuestión que es más propia de los órganos del Estado que ejercen funciones jurisdiccionales, cuales son los Tribunales de Justicia principalmente.

El camino que podría seguir la Inspección del Trabajo es solicitar la disolución del sindicato ilícito ante el Tribunal del Trabajo competente, fundado en que el mismo incumplió gravemente las obligaciones que le impone la ley, específicamente, que no persigue ninguno de los fines que le son propios, sino objetivos espurios, que constituyen un atentado en contra de la libertad sindical misma, defraudando el espíritu de normas de naturaleza imperativa e infringiendo diversos principios que imperan en el Derecho del Trabajo. Sin embargo, el problema que presenta esta posibilidad es que parece desprenderse del artículo 297 inciso $1^{\circ}$ del Código del Trabajo que la disolución de una organización sindical fundado en incumplimiento grave a las obligaciones que le impone la ley solamente procede cuando un sindicato que en su constitución cumplió con todos los requisitos formales y sustanciales y, por tanto, fue constituido con fines lícitos, durante su existencia contraviene las obligaciones legales. De ser así, no es posible solicitar la disolución de un sindicato basado en que fue constituido con abuso del derecho o en fraude a la ley, ya que tal infracción se comete en el acto mismo de constitución de la organización sindical, y no durante su existencia, no encontrándose dichas situaciones entre los supuestos fácticos subsumibles en la norma contenida en el artículo 297 del Código del Trabajo.

Para superar esta dificultad es perfectamente procedente que la Inspección del Trabajo ejerza una acción de nulidad absoluta o bien de inoponibilidad por fraude a la ley o por abuso del derecho, dependiendo del tipo de sindicato constituido ilícitamente y de la sanción que estime procedente ${ }^{43}$. Diversas normas jurídicas comprueban la legitimación activa de la Inspección del Trabajo para ejercer alguna de estas acciones. Si es el órgano del Estado encargado de velar por el debido respecto de las normas sindicales, fiscalizando la aplicación de las normas laborales, tal como lo disponen los artículos 505 del Código del

\footnotetext{
${ }^{43}$ Véase sobre la sanción de los sindicatos constituidos con fines ilícitos FernÁNDEZ (2014 a), pp. 277281 y $293-297$.
} 
Trabajo y 1 letra a) del decreto con fuerza de ley $N^{\circ} 2$ de 1967, del Ministerio del Trabajo y Previsión Social, debe permitírsele accionar ante los Tribunales de Justicia en los casos que detecta que en la constitución de un sindicato no se persiguen fines lícitos, al no tener la facultad de poder sancionarlo ella misma.

Al verse vulnerado un derecho fundamental con la constitución de un sindicato ilícito, como lo es la libertad sindical, se entiende implícito un interés público en esta circunstancia, constituyendo la situación justificante de la legitimación activa de la Inspección del Trabajo, la cual tiene por misión poner en movimiento la actividad jurisdiccional de los Tribunales de Justicia en defensa de la legalidad y del interés público tutelado por las leyes laborales, de oficio o a petición de algún interesado, como puede ser el empleador o los trabajadores.

La posibilidad de accionar judicialmente por parte del mencionado Servicio Público no solamente permite sancionar una conducta que atenta contra el derecho fundamental de libertad sindical, sino que también permite garantizar la vigencia del orden público laboral. El derecho de constituir sindicatos y la libertad de empresa, además de ser derechos subjetivos de rango constitucional, derechos de los individuos, en cuanto garantizan un status jurídico o la libertad en un ámbito de existencia, son elementos esenciales en el Derecho del Trabajo, permitiendo una coexistencia de intereses diversos, de trabajadores, sindicatos y empleadores. Por ello es que el ordenamiento jurídico laboral ha desvinculado la tutela de los derechos y libertades fundamentales de tu titularidad, y ha encomendado también su defensa al Estado a través de la Inspección del Trabajo.

La legitimación de la Inspección del Trabajo para solicitar la sanción de los sindicatos ilícitos es una legitimación compartida. Quiere ello decir que actúa siempre que el interés público reconocido en las normas sindicales lo requieran, pero con independencia de la acción que corresponde al titular del derecho, interés o situación jurídica que ha resultado lesionado con el sindicato espurio. Pero también es una legitimación propia y no una legitimación por sustitución de los particulares afectados.

En todo caso se reconoce que es discutible la legitimación activa de la Inspección del Trabajo para solicitar la sanción de los sindicatos constituidos con fines ilícitos, debido a que es posible sostener que la Inspección del Trabajo solamente puede accionar judicialmente cuando una disposición legal expresa le confiere legitimación para ello, como ocurre con la acción de práctica antisindical (artículo 292 inciso $4^{\circ}$ del Código del Trabajo), con la acción de disolución de sindicatos que incumplen gravemente las obligaciones que les impone la ley (artículo 296 del Código del Trabajo), con la acción de práctica desleal (artículo 389 inciso final del Código del Trabajo) y la acción de tutela laboral (artículo 486 inciso $5^{\circ}$ del Código del Trabajo), entre otras situaciones mencionadas expresamente por el legislador, no teniendo legitimación activa en supuestos no reconocidos por la legislación. De este modo, podría soste- 
nerse que al no estar admitida por ninguna norma jurídica la legitimación de la Inspección del Trabajo para solicitar la sanción de los sindicatos constituidos con fines ilícitos, carece de legitimación activa.

\section{b) Legitimación activa del empleador}

Tratándose de la legitimación activa del empleador para solicitar la sanción de un sindicato constituido con fines ilícitos, sea fundado en una acción, excepción o alegación de fondo, bien su nulidad o su inoponibilidad, en la jurisprudencia judicial existen dos posiciones distintas y contrapuestas. Una que le niega legitimación activa y otra que la admite.

i) El empleador carece de legitimación activa. Una posición jurisprudencial sostiene que el empleador no es el titular para impugnar el acto constitutivo de una organización sindical, los efectos derivados del mismo, ni tampoco sus actos eleccionarios, recurriéndose para ello a la historia de la ley y al tenor literal de ciertas normas legales ${ }^{44}$. Se indica como fundamento de esta conclusión las modificaciones legales introducidas al Código del Trabajo por la ley $N^{\circ} 19.759$, que eliminó al empleador como sujeto activo de la solicitud de disolución de un sindicato, facultad que sí estaba contemplada en la redacción del antiguo artículo 295 del Código del Trabajo, que fue modificado por la ley indicada con el propósito de tutelar con más fuerza la garantía de la libertad sindical reconocida constitucionalmente. Agrega este criterio jurisprudencial que, por lo demás, en la actualidad sólo la autoridad administrativa puede realizar observaciones a la constitución de un sindicato, facultad establecida y regulada en el artículo 223 del Código del Trabajo, no figurando el empleador como titular de la misma en dicho artículo ni en ninguna otra disposición legal. En efecto, conforme a lo dispuesto en los artículos 223, 296 y 297 del Código del Trabajo, el empleador carecería de legitimación para solicitar la sanción de los sindicatos constituidos con fines ilícitos, conclusión que se vería reforzada por la libertad sindical, garantizada tanto a nivel legal como constitucional e, incluso, en numerosos tratados internacionales sobre derechos humanos, que impiden toda injerencia del empleador en su ejercicio.

${ }^{44}$ En este sentido Juzgado de Letras del Trabajo de Antofagasta, RIT S-3-2009, 13 de noviembre de 2009; Juzgado de Letras del Trabajo de Antofagasta, RIT S-4-2009, 26 de noviembre de 2009; Segundo Juzgado de Letras del Trabajo de Santiago, RIT T-26-2009, 18 de diciembre de 2009; sentencia del Segundo Juzgado de Letras del Trabajo de Santiago, RIT O-348-2009, 29 de diciembre de 2009; Segundo Juzgado de Letras del Trabajo de Santiago, RIT T-43-2009, 11 de enero de 2010; Corte de Apelaciones de Santiago, Rol Reforma Laboral № 65-2010, 7 de junio de 2010; Corte de Apelaciones de Talca, Rol Reforma Laboral № 87-2011; 29 de septiembre de 2011; Corte de Apelaciones de Santiago, Rol Reforma Laboral No 591-2012, 6 de julio de 2012. 
ii) El empleador tiene legitimación activa. También es posible encontrar jurisprudencia judicial que no ha negado la legitimación activa al empleador para cuestionar la constitución de un sindicato ilícito. Es así que en ciertas oportunidades se ha acogido la acción de nulidad absoluta del sindicato ejercida por el empleador, rechazándose toda objeción sobre la legitimación activa del empleador ${ }^{45}$. También, existen numerosas sentencias en que se admite que el empleador puede solicitar la ineficacia de los efectos derivados de un sindicato constituido en fraude a la ley o con abuso del derecho, generalmente mediante el ejercicio de una acción o excepción fundada en la inoponibilidad por fraude o abuso del derecho ${ }^{46}$.

La posición jurisprudencial que niega legitimación activa al empleador para utilizar los medios procesales que estime necesarios para obtener la sanción de los sindicatos ilícitos, sea cuando se solicite su nulidad absoluta o la inoponibilidad del sindicato o bien de sus efectos, no tiene sustento normativo, toda vez que no resultan aplicables los artículos 223, 296 y 297 del Código del Trabajo cuando se persigue sancionar una organización sindical constituida con propósitos instrumentales. Ello porque el artículo 223 del Código del Trabajo únicamente regula la facultad de la Inspección del Trabajo para fiscalizar y sancionar los defectos formales del acto de constitución sindical, mas no los requisitos sustantivos del mismo, constituido por el animus sindicali. De ahí que el empleador sólo carecería de legitimación activa para cuestionar los requisitos formales de constitución de un sindicato, mas no los sustantivos, los que perfectamente podría impugnar por los medios que estime necesarios y legalmente admisibles. Por lo demás, ni el artículo 223 del Código del Trabajo ni ninguna otra norma jurídica prohíben expresamente al empleador impugnar la constitución de un sindicato o al menos sus efectos, cuando carecen de ánimo colectivo, no existiendo sustento legal para negarle tal posibilidad.

Por otro lado, los artículos 296 y 297 del Código del Trabajo, si bien confieren la titularidad a los socios y a la Inspección del Trabajo para solicitar la disolución de una organización sindical y no al empleador, no son aplicables cuando se cuestiona la constitución de un sindicato por parte del empleador por perseguir fines ilícitos, toda vez que los artículos 296 y 297 presuponen

\footnotetext{
45 Juzgado de Letras del Trabajo de Valdivia, RIT O-117-2010, 13 de noviembre de 2010; Juzgado de Letras del Trabajo de San Miguel, RIT O-45-2013, 30 de mayo de 2013.

${ }^{46}$ Juzgado de Letras del Trabajo de Valparaíso, 20 de mayo de 2009, RIT S-4-2009; Juzgado de Letras del Trabajo de Valparaíso, 20 de mayo de 2009, RIT S-7-2009; Primer Juzgado de Letras del Trabajo de Santiago, RIT S-44-2010, 9 de noviembre de 2010; Segundo Juzgado de Letras del Trabajo de Santiago, RIT S-56-2011, 18 de noviembre de 2011; Segundo Juzgado de Letras del Trabajo de Santiago, RIT I-2922011, 26 de enero de 2012; Segundo Juzgado de Letras del Trabajo de Santiago, RIT I-305-2011, 16 de febrero de 2012; Primer Juzgado de Letras de Santiago, RIT S-106-2011, 23 de marzo de 2012, entre otras.
} 
que el sindicato en su constitución cumplió todas las exigencias formales y sustantivas, pero que durante su vida incumplió gravemente sus obligaciones legales. En cambio, cuando un sindicato es constituido con abuso del derecho o en fraude a la ley, se está ante un sindicato que no es tal, que no cumple con todas las exigencias de constitución, al carecer del ánimo colectivo, requisito de existencia del mismo. Es por ello que no procede invocar tampoco los artículos 296 y 297 del Código del Trabajo para negar la titularidad al empleador para cuestionar un sindicato ilícito. Dicha conclusión está acorde con el derecho a la tutela judicial ${ }^{47}$, garantía constitucional prevista de forma implícita en el artículo $19 \mathrm{~N}^{\circ} 3$ inciso $1^{\circ}$ de la Constitución Política, conforme a la cual es un derecho fundamental de toda persona obtener la efectiva protección de sus derechos subjetivos y de los intereses legítimos de parte de los Tribunales de Justicia cuando resultan lesionados ilegítimamente, siendo evidente que cuando en la empresa se constituye un sindicato meramente instrumental se vulnera tanto la libertad de empresa como el derecho de propiedad del empleador y los derechos que son concreción de dichas garantías reconocidos por la legislación laboral, debido a que el mismo genera diversos efectos perjudiciales para el empleador, entrabando su poder de dirección y/o disciplinario, causando generalmente perjuicios a su patrimonio.

Es por lo antes expuesto que no cabe duda que el empleador debe ser el primer legitimado para disponer de los mecanismos legales necesarios tendientes a obtener la sanción de las organizaciones sindicales ilícitas, de lo contrario se corre el riesgo que los mismos no sean sancionados, cuando ninguno de los demás legitimados solicita su sanción, legitimándose y amparando un acto que lesiona no solo los derechos e intereses del empleador, sino también al ordenamiento jurídico mismo.

Impedir al empleador que cuestione la formación o constitución de un sindicato ilícito es un error de derecho, debido a que importa privar de una acción a quien tiene un interés legítimo y actual, privación que no es aceptable en un Estado de Derecho. Así lo dan a entender ciertas sentencias judiciales de la Corte Suprema ${ }^{48}$.

De ahí que estimamos que la posición jurisprudencial que reconoce legitimación activa al empleador es la más ajustada a derecho. No solamente porque no procede invocar las normas que regulan el control formal del acto de constitución sindical y la disolución de los sindicatos, sino que también porque guarda coherencia con el derecho de la tutela judicial efectiva de que es titular

\footnotetext{
47 Véase sobre el tema Bordalí (2011), pp. 311-337; García y Contreras (2013), pp. 229-282.

${ }^{48}$ Corte Suprema, rol № 365-2008, 8 de abril de 2008; Corte Suprema, rol № 368-2008, 8 de abril de 2008.
} 
el empleador, la cual tiene rango constitucional al ser un derecho fundamental consagrado en el artículo 19 NN$^{\circ} 3$ inciso $1^{\circ}$ de la Constitución Política. El mismo garantiza el derecho de toda persona a que se haga justicia, que se traduce en el plano jurídico laboral en que siempre que estime un sujeto de derecho que puede pretender algo con arreglo a derecho de un Tribunal de Justicia, tenga la seguridad de que su petición será atendida por un órgano independiente e imparcial. Negar su titularidad al empleador respecto de la posibilidad de impugnar los sindicatos ilícitos, se traduce en que carecería de sentido que nuestra Carta Fundamental se hubiese esmerado en asegurar la igual protección de la ley en el ejercicio de los derechos, si no partiera de la base de la existencia de un derecho anterior a todos los demás, y que es presupuesto básico para su vigencia, esto es, el derecho de recurrir ante el juez sin impedimentos que no tienen ningún sustento normativo ${ }^{49}$.

Denegar la legitimación del empleador para solicitar la sanción de un sindicato ilícito constituido por trabajadores dependientes que le prestan servicios es negar la existencia misma del derecho a la tutela judicial efectiva y, a la vez, desconocer la vigencia de la libertad de empresa y el derecho de propiedad junto a los derechos de rango legal que constituyen concreción de estos derechos fundamentales, amparando la infracción al ordenamiento jurídico, lo que no es admisible en un Estado Democrático de Derecho, como es el nuestro.

\section{c) La legitimación activa de los trabajadores y sindicatos}

Es posible sostener que los trabajadores u organizaciones sindicales que tengan interés en solicitar la sanción de los sindicatos constituidos con fines ilícitos, perfectamente pueden ejercer las acciones correspondientes, debiendo necesariamente invocar y acreditar para ello al menos un interés legítimo actual ${ }^{50}$. Ello porque en esta materia no existe una acción popular, siendo, por tanto, necesario invocar un interés legítimo, pues sin el mismo no hay acción para poner en movimiento el aparato jurisdiccional. Dicha posibilidad, si bien no ha sido reconocida expresamente por el legislador, con la salvedad de la disolución de las organizaciones sindicales, donde tienen legitimación los trabajadores constituyentes en la forma dispuesta por el artículo 296 del Código del Trabajo, tampoco ha sido negada, debiendo prevalecer la conclusión que

49 VARELA (2009), p. 154.

${ }^{50}$ El interés es una de las situaciones legitimantes, es decir, una de las categorías jurídicas sustanciales que en el caso concreto sirven para determinar la concurrencia de la legitimación activa, en este sentido ROMERO (2006), pp. 88-91. En sentido positivo el interés se define por Couture como "la aspiración legítima de orden pecuniario o moral, que representa para una persona la existencia de una situación jurídica o la realización de una determinada conducta", Couture (1993), p. 344. 
concede legitimación activa a los trabajadores y sindicatos, al estar más acorde con la garantía de la tutela judicial efectiva de los derechos de las personas.

Tratándose de los trabajadores que constituyeron un sindicato con fines ilícitos, sea en calidad de autores, cómplices o bien que concurrieron de buena fe, ignorando el fin espurio que perseguían algunos trabajadores, surge la duda de si tienen legitimación activa para solicitar la sanción del mismo sindicato que contribuyeron a constituir. Sea que se estime que la sanción del sindicato es la inoponibilidad o la nulidad absoluta, de aplicarse lisa y llanamente el principio "nemo auditur", de amplia acogida en el derecho nacional como medio para privar del derecho a alegar la ilicitud a los que han intervenido directa o indirectamente en el acto, no podrían alegar que el sindicato fue constituido con abuso del derecho o en fraude a la ley en que han participado como autores, cómplices o constituyentes de buena $\mathrm{fe}^{51}$. Sin embargo, si se consideran los principios y valores jurídicos propios del Derecho del Trabajo que resultan vulnerados por el sindicato con fines ilícitos, forzoso es concluir que los mismos deben prevalecer sobre la regla del nemo auditur-propio del Derecho Civil-toda vez que todo acto que atenta contra la libertad sindical debe ser sancionado sin importar quien solicite su sanción. Debido a la trascendencia de los valores y principios vulnerados con los sindicatos ilícitos, debe primar la posibilidad de sancionar los sindicatos ilícitos frente a quien solicita la sanción. El interés público está por sobre el interés individual, debiendo primar la vigencia efectiva del ordenamiento jurídico laboral.

\subsection{Legitimación procesal pasiva}

Para que el ejercicio de una acción fundada en la constitución ilícita de un sindicato pueda prosperar, no basta con que se impetre por alguno de los sujetos de derecho que detenta la legitimación activa. También es necesario que se ejerza en contra del legitimado pasivo. No existe claridad al respecto, debido a que no existe norma expresa que regule la legitimación pasiva. Sin embargo, teniendo presente los juicios conocidos por los Tribunales de Justicia, los legitimados pasivos pueden ser el sindicato constituido con fines ilícitos, la Inspección del Trabajo y los trabajadores constituyentes que han participado en la constitución como autores o cómplices.

i) No existen dudas que cuando se solicita la sanción misma del sindicato constituido con fines ilícitos el legitimado pasivo es dicho sindicato. Si bien puede parecer contradictorio que se demande a un sindicato que se estima que en realidad no existe por carecer de animus sindicali, porque por una parte se le está demandado como un sujeto de derecho, y por otra se está solicitando su

51 Domínguez (1991), p. 32. 
sanción, que, incluso, puede ser su eliminación absoluta del sistema jurídico laboral, si se alega y declara su nulidad, esta contradicción no es tal, porque mientras el Tribunal de Justicia competente no sancione al sindicato ilícito en virtud de una sentencia judicial firme, el mismo existe en la vida del derecho como sujeto de derecho, y en tal calidad puede ser demandado. El único caso conocido por un Tribunal de Justicia nacional donde se accionó de nulidad absoluta contra un "sindicato del día después" fue acogido, no habiendo existido inconvenientes de legitimidad pasiva para ello ${ }^{52}$. Lo mismo ocurrió en otro caso en que se declaró la nulidad de un sindicato ${ }^{53}$.

Al tener las sentencias judiciales efectos relativos por regla general, producen eficacia solamente respecto de las partes litigantes de la causa en que se pronuncia (artículo $3^{\circ}$ del Código Civil), por lo que no se podría solicitar la ineficacia del acto constitutivo sindical mismo demandando a los trabajadores constituyentes o a la Inspección del Trabajo. De demandarse a alguno de estos sujetos solicitando la nulidad absoluta o la inoponibilidad del sindicato ilícito, el Tribunal de Justicia que conozca del juicio deberá rechazar la demanda por falta de legitimidad pasiva, y de acogerse la demanda, esta sentencia no produce efectos respecto del sindicato, el cual seguirá existiendo en la vida del derecho.

Podría demandarse por el empleador en un mismo juicio al sindicato ilícito y a los trabajadores constituyentes, pero ejerciéndose distintas acciones a través de la acumulación sucesiva de acciones, donde se ejerce la acción de inoponibilidad o de nulidad absoluta contra el sindicato, pero subordinada a la estimación de la misma que le precede se ejerce una acción de reembolso por las remuneraciones y beneficios económicos que otorgó sobre la base del sindicato ilícito o de indemnización de perjuicios contra todos o algunos de los trabajadores constituyentes. Sin embargo, si no se accede a la acción contra el sindicato, la acción contra los trabajadores debe ser rechazada, que es, precisamente, el efecto propio de la acumulación sucesiva ${ }^{54}$. En tal caso se configura una litis consorcio voluntaria pasiva, esto es, una pluralidad de partes demandadas, que no es obligatoria pero sí permitida por el legislador.

ii) También puede ser legitimado pasivo la Inspección del Trabajo, pero no para demandar la sanción del sindicato ilícito sino para solicitar al Tribunal de Justicia competente dejar sin efecto una multa aplicada por la Inspección del Trabajo al empleador de los trabajadores constituyentes fundado en no respetar

\footnotetext{
52 Juzgado de Letras del Trabajo de Valdivia, RIT O-117-2010, 13 de noviembre de 2010.

53 Juzgado de Letras del Trabajo de San Miguel, RIT O-45-2013, 30 de mayo de 2013.

${ }^{54}$ La acumulación sucesiva se define como aquella en la que se formula un pedimento subordinado a la estimación de otro que le precede, de tal suerte que si no se accede al primero, el segundo no tiene sentido, Romero (2011), p. 259. Véase sobre la acumulación sucesiva de acciones Prieto-CASTro (1985), pp. 473-474.
} 
alguno de los derechos o prerrogativas que emanan del sindicato constituido con abuso del derecho o en fraude a la ley.

Debido a que la Inspección del Trabajo efectúa un control de los requisitos formales de constitución del sindicato, no formula observaciones al sindicato constituido con fines ilícitos y, por tanto, lo considera correctamente constituido. Es por ello que existe la posibilidad que sancione al empleador que no respeta el fuero sindical, los permisos sindicales y demás prerrogativas que derivan de la constitución de un sindicato, generalmente mediante la imposición de una multa. Ante esta situación el empleador puede reclamar judicialmente ante los Juzgados de Letras del Trabajo solicitando que se deje sin efecto la multa, debido a que el sindicato fue constituido con fines ilícitos, siendo, por tanto, ineficaces los efectos derivados de su constitución a su respecto. Es así como los Juzgados de Letras del Trabajo han conocido de reclamos judiciales en que han dejado sin efecto la multa aplicada por la Inspección del Trabajo al empleador por no respetar el fuero sindical derivado de la constitución de un sindicato del día después, sosteniendo que dicho fuero es ineficaz respecto del empleador, por lo que no pudo vulnerar las normas que regulan el fuero sindical ${ }^{55}$.

iii) Finalmente, pueden ser legitimados pasivos los trabajadores constituyentes del sindicato formado con fines ilícitos para reclamar diversas pretensiones derivadas del sindicato constituido con abuso del derecho o en fraude a la ley, pudiendo señalarse los casos conocidos por los Tribunales de Justicia.

Ante la constitución de un sindicato ilícito, especialmente del día después, y la decisión de la Inspección del Trabajo de obligar a reincorporar un trabajador despedido que es elegido representante de los trabajadores, el empleador puede solicitar el desafuero de dichos trabajadores, fundado en que han participado en la constitución de un sindicato con el solo propósito de gozar de fuero sindical y dejar sin efecto el despido, lo que importa incurrir en falta de probidad o al menos en un incumplimiento grave de las obligaciones que impone el contrato. De gran claridad resulta un caso en que el empleador despidió a un trabajador por la causal de necesidades de la empresa, sin embargo, días después le llegó una comunicación informando que el trabajador despedido había sido elegido delegado sindical en un sindicato interempresas. La Inspección del Trabajo obligó a reincorporarlo, ordenándole pagar las remuneraciones durante el tiempo que estuvo ilegalmente separado. Luego el trabajador fue elegido delegado sindical en otro sindicato interempresas para garantizar su inmovilidad en el empleo. Ante tal escenario el empleador demandó de desafuero a ese trabajador. Se logró acreditar que los sindicatos tenían diversas irregularidades, y que el trabajador

\footnotetext{
${ }^{55}$ Segundo Juzgado de Letras del Trabajo de Santiago, RIT I-292-2011, 26 de enero de 2012; Segundo Juzgado de Letras del Trabajo de Santiago, RIT I-305-2011, 16 de febrero de 2012.
} 
fue elegido delegado sindical solamente para dejar sin efecto el despido y obtener inmovilidad laboral, determinando el tribunal que en tal escenario es clara y evidente la instrumentalización fraudulenta efectuada por el demandado, quien ante la decisión de su empleador de poner término a sus servicios, en virtud de la causal establecida en el artículo 161 inciso $1^{\circ}$ del Código del Trabajo, mal utiliza la institución de protección que concede el ordenamiento jurídico laboral, otorgándose un fuero que sólo implica un beneficio propio y particular, al generarle en primer término estabilidad en el empleo con su reincorporación y, como consecuencia de ello, el pago de prestaciones en un tiempo superior al querido y pretendido por su empleador, dando lugar al desafuero ${ }^{56}$.

También es posible demandar a trabajadores despedidos, ejerciendo el empleador una acción de mera certeza para solicitar a los Juzgados de Letras del Trabajo la declaración de que el trabajador despedido ha abusado de las prerrogativas establecidas en las disposiciones de los artículos 221 inciso $3^{\circ}$ y 243 inciso $1^{\circ}$ del Código del Trabajo, al concurrir a la constitución de un sindicato del día después con el único objeto de dejar sin efecto su despido, obtener su reincorporación e inmovilidad laboral, siendo el fuero ineficaz, y como consecuencia de lo mismo, el despido efectuado es válido y eficaz ${ }^{57}$.

Por otro lado, los trabajadores constituyentes pueden ser demandados por parte del empleador, reclamando la restitución de las sumas de dinero pagadas a título de remuneraciones y cotizaciones previsionales a causa del sindicato ilícito, e incluso solicitar una indemnización de perjuicios por los daños que han causado al empleador con la constitución de un sindicato ilícito. No existen antecedentes jurisprudenciales al respecto, pero es perfectamente admisible, por aplicación de las reglas generales de la responsabilidad civil contractual o extracontractual, según el estatuto que se estime aplicable.

\section{Instrumentos de que disponen los legitimados activos para obtener la sanción de los sindicatos constituidos con fines ilícitos}

Teniendo presente que las contiendas en que se discute la existencia de un sindicato constituido con fines ilícitos son de competencia de los Tribunales de Justicia -y en nuestro concepto de los Juzgados de Letras del Trabajo- corresponde determinar cuáles son los mecanismos legales de que disponen los legitimados activos para solicitar al juez competente la sanción de un sindicato constituido con fines ilícitos o bien la ineficacia de los efectos derivados de un

\footnotetext{
56 Primer Juzgado de Letras del Trabajo de Santiago, RIT O-3499-2011, 20 de enero de 2012.

57 Segundo Juzgado de Letras del Trabajo de Santiago, RIT O-2574-2011, 18 de noviembre de 2011, que acoge la acción de mera certeza ejercida por el empleador contra trabajador despedido.
} 
sindicato de dicha naturaleza, como también cuál es el procedimiento en que deben utilizarse dichos mecanismos.

\subsection{La acción y excepción para solicitar la sanción de los sindicatos constituidos con fines ilícitos}

Al regir en nuestro proceso laboral el principio dispositivo ${ }^{58}$, cuya característica esencial es que las partes tienen la carga procesal de formular las alegaciones ante el Tribunal de Justicia con competencia laboral, introduciendo en el proceso los hechos y pretensiones que desean sean discutidas y resueltas, los instrumentos de que disponen los sujetos que son legitimados activos para alegar la existencia de un sindicato constituido con fines ilícitos son la acción ${ }^{59}$ y la excepción ${ }^{60}$.

Por otro lado, según se indicó, dos son las posibles sanciones de aplicar a los sindicatos constituidos con fines ilícitos: la nulidad absoluta y la inoponibilidad. Derivado de esta circunstancia, la acción y la excepción pueden tener una pretensión de inoponibilidad o bien de nulidad absoluta, lo que dependerá de la sanción que el legitimado activo solicite para el sindicato ilícito.

i) La inoponibilidad es normalmente una excepción, incluso puede señalarse que esta es su naturaleza propia, pues tiene como finalidad hacer ineficaz el acto inoponible como si este no existiere frente al tercero que desconoce el acto, cuando, precisamente, se pretende hacerlo valer en su contra ${ }^{61}$. De este modo, frente a un sindicato constituido con fines ilícitos cuya existencia y eficacia se pretenda hacer valer en juicio, especialmente respecto del empleador, cuando se desconoce en la realidad de facto, este puede alegar la inoponibilidad por fraude a la ley o abuso del derecho a través de una excepción perentoria. En otros términos, frente a una demanda del sindicato constituido con abuso del derecho o en fraude a la ley en que solicite a un Tribunal de Justicia una declaración judicial de reconocimiento del sindicato o bien que el empleador de sus trabajadores afiliados reconozca algunos de los efectos derivados de su constitución, el empleador demandado puede oponer como excepción perentoria la inoponibilidad, solicitando al tribunal que declare que a su respecto sea inoponible el sindicato abusivo o constituido en fraude a la ley. En este caso, de acogerse la excepción, se declarará mediante sentencia judicial que es ino-

\footnotetext{
${ }^{58}$ Véase sobre la vigencia del principio dispositivo en el proceso laboral FERNÁNDEZ (2011a), pp. 18-30; FERNÁNDEZ (2011 b), pp. 40-44.

59 Véase un resumen de las distintas teorías de la acción en Devis (1966), pp. 154-200; ChIOvendA (1992), pp. 15-43; GUASP (2002), pp. 231-236.

${ }^{60}$ Véase sobre las excepciones Couture (1981), pp. 87-90.

${ }^{61}$ Domínguez (1991), p. 31.
} 
ponible el sindicato ilícito respecto de quien opone la excepción, declaración judicial con efectos relativos, porque solamente tiene eficacia entre las partes litigantes del proceso en que se dictó la sentencia que declaró la inoponibilidad del acto de constitución sindical.

Sin embargo, en ciertas oportunidades la víctima o legitimado activo puede tener un legítimo interés en demandar mediante una acción la declaración de inoponibilidad $^{62}$. Dicho interés es claro tratándose del empleador de los trabajadores constituyentes del sindicato ilícito, pues el mismo le causa perjuicio al empleador al trabar sus poderes de dirección, administración y disciplinario, al arrogarse las prerrogativas que el legislador concede a los sindicatos constituidos con fines lícitos. Pero también existe un interés legítimo en los demás legitimados activos, el cual no necesariamente está constituido por un perjuicio o provecho económico, sino por la supervigilancia de la vigencia de la legislación laboral, tratándose de la Inspección del Trabajo. De acogerse la acción de inoponibilidad, lo que ocurrirá en la sentencia definitiva, surge un estado jurídico que priva de efectos al acto de constitución sindical para proteger la situación ${ }^{63}$ del legitimado activo. Sin embargo, el sindicato ilícito solamente será inoponible respecto del demandante que ejerció la acción, debido a los efectos relativos de la inoponibilidad. Los demás legitimados activos si pretenden la inoponibilidad del sindicato ilícito deben ejercer la acción de inoponibilidad, para que la misma sea declarada por el Tribunal de Justicia competente a su respecto.

La jurisprudencia judicial se ha pronunciado sobre la inoponibilidad del acto de constitución sindical cuando se ha solicitado a través de una acción. El Segundo Juzgado de Letras del Trabajo de Santiago conociendo de una acción de mera certeza del despido de un trabajador que participó en la constitución de un sindicato del día después ejercida por el empleador, que se acumuló a una acción de práctica antisindical ejercida por el trabajador despedido, en que el empleador solicitó la declaración de validez del despido y de ineficacia del fuero derivado de la constitución del sindicato, declaró la inoponibilidad del acto jurídico de constitución del sindicato respecto del empleador y la validez del despido ${ }^{64}$.

ii) La nulidad absoluta se encuentra regulada en el Código Civil en los artículos 1681 y siguientes, siendo su aplicación procedente en el Derecho del Trabajo de modo supletorio. Su alegación se efectúa normalmente como excepción, lo que ocurre cuando se pretende invocar ante un Tribunal de

62 Romero (2011), p. 256. El profesor Abeliuk también sostiene que "la inoponibilidad se puede hacer valer como acción o excepción", en Aвelıuk (2003), p. 160.

${ }^{63}$ Romero (2011), p. 256.

${ }^{64}$ Segundo Juzgado de Letras del Trabajo de Santiago, RIT O-2574-2011, 18 de noviembre de 2011. 
Justicia la eficacia del acto jurídico que adolece de un vicio de nulidad, caso en el cual el demandado opone la excepción perentoria de nulidad absoluta ${ }^{65}$, lo que, tratándose del sindicato constituido con abuso del derecho o en fraude a la ley, se traducirá en que el demandado -especialmente el empleador, que es generalmente el demandado- enerve la pretensión reclamada en su contra a través de la excepción de nulidad absoluta por objeto y/o causa ilícita y carecer de animus sindicali, que son, precisamente, los vicios que concurren en la constitución de sindicatos con fines ilícitos, solicitando el rechazo de la acción.

Tampoco existe inconveniente en que el legitimado activo solicite la nulidad absoluta de un sindicato ilícito mediante el ejercicio de una acción, pues si se tiene interés legítimo y actual, se tiene acción, no habiéndose negado la misma cuando se solicita la nulidad absoluta de un acto jurídico civil, donde se encuentra regulada esta sanción ${ }^{66}$. Existe solamente un juicio conocido por los Tribunales de Justicia con competencia laboral donde se declaró la nulidad absoluta de un "sindicato del día después". El mismo fue conocido por el Juzgado de Letras del Trabajo de Valdivia, en que el empleador ejerció en lo principal de la demanda una acción de nulidad absoluta por objeto y causa ilícita del acto de constitución del sindicato en contra del sindicato mismo, la que fue acogida por el tribunal, declarando la nulidad absoluta de dicho sindicato ${ }^{67}$. Asimismo, existe otro caso en que se declaró la nulidad del sindicato por diversos defectos en su constitución, solicitada por el empleador ${ }^{68}$.

\subsection{Acumulación de acciones}

Tratándose de las acciones de nulidad absoluta y de inoponibilidad, se pueden ejercer otras acciones conjuntamente a alguna de ellas, que son conexas, como lo puede ser la acción de restitución ejercida por el empleador en contra de los trabajadores que se beneficiaron con la constitución de un sindicato ilícito, obteniendo permisos sindicales, fuero sindical, remuneraciones y cotizaciones previsionales al margen del derecho. Tal posibilidad es admitida expresamente por el Código de Procedimiento Civil, al admitir y regular la pluralidad de acciones en el artículo 17, precepto que es pertinente en el proceso laboral en virtud de la aplicación supletoria del libro I del Código de Procedimiento Civil, donde se encuentra ubicado el artículo 17, conforme a lo dispuesto en

\footnotetext{
65 Rodríguez (2004), pp. 230-232; Alessandri (2011), pp. 592-599; Domínguez (2013), pp. $212-213$.

66 Rodríguez (2004), pp. 231-232; Barcia (2007), p. 141-142; Alessandri (2011), pp. 581-582; DomínGUEZ (2013), pp. 212.

67 Juzgado de Letras de Valdivia, RIT O-117-2010, 13 de noviembre de 2010.

68 Juzgado de Letras del Trabajo de San Miguel, RIT O-45-2013, 30 de mayo de 2013.
} 
el artículo 432 del Código del Trabajo. La acción de nulidad absoluta o de inoponibilidad se dirigirá en contra del sindicato ilícito, y la de restitución en contra de los trabajadores constituyentes que obtuvieron beneficios indebidos, existiendo una acumulación de acción objetivo-subjetivo y también un litis consorcio voluntario pasivo, al ser varios los demandados.

Asimismo, las acciones de nulidad y de inoponibilidad se pueden ejercer en una misma demanda contra el sindicato ilícito, pero debido a que son incompatibles entre sí, por fundarse en vicios y supuestos distintos, deben ejercerse en forma subsidiaria, posibilidad también admitida por el artículo 17 del Código de Procedimiento Civil.

\subsection{Acción para reclamar la ineficacia de sanciones aplicadas a consecuencia de un sindicato ilícito}

Debido a que el sindicato ilícito tiene la apariencia de ser un sindicato en que se han cumplido todas las exigencias legales, calidad que conserva mientras no sea declarado como tal por una sentencia judicial, es de frecuente ocurrencia que la Inspección del Trabajo en el ejercicio de su función fiscalizadora constate infracciones por parte del empleador a la normativa laboral sobre sindicatos, que afectan a los trabajadores constituyentes y representantes sindicales, especialmente las normas legales que regulan el fuero sindical. El caso de más común ocurrencia en la práctica es aquél en que despedido uno o más trabajadores constituyen junto a otros empleados un sindicato dentro de los 10 días siguientes con el solo propósito de dejar sin efecto el despido y obtener su reincorporación e inmovilidad, de ser elegidos directores sindicales en el acto de constitución sindical. Los trabajadores interponen una denuncia a la Inspección del Trabajo, la cual solicita al empleador la reincorporación de los trabajadores constituyentes despedidos porque, en su concepto, gozaban del fuero retroactivo del artículo 221 del Código del Trabajo al momento del despido no habiéndose solicitado autorización judicial para la desvinculación, el que, por tanto, sería nulo. El empleador a veces se niega a la reincorporación por estimar que el fuero es ineficaz por ser el sindicato fraudulento, ante lo cual la Inspección del Trabajo procede a aplicarle una multa por infracción de las normas que regulan el fuero sindical, lo que ha ocurrido en diversas oportunidades.

Frente a una multa aplicada por infracción al fuero sindical nacido de un sindicato constituido con fines ilícitos, el empleador tiene la posibilidad de ejercer una acción procesal, reclamando judicialmente de la multa aplicada por la Inspección del Trabajo. Lo que se traduce en que el empleador solicita al Juzgado de Letras del Trabajo competente que deje sin efecto la multa por ser improcedente, debido a que el fuero nacido de un sindicato constituido con abuso del derecho o en fraude a la ley es ineficaz, no habiendo existido, por 
tanto, infracción a las normas que regulan el fuero sindical. Existen diversas sentencias judiciales que han acogido los reclamos judiciales de multa interpuestos por el empleador contra la Inspección del Trabajo, dejando sin efecto la resolución de multa, fundado en que se acreditó en el juicio que el sindicato del cual nació el fuero sindical fue constituido con abuso del derecho, siendo, por tanto, ineficaz el fuero nacido de tal sindicato, porque se ha perseguido con el mismo un fin totalmente distinto al previsto por el legislador, cual es dejar solamente sin efecto el despido ${ }^{69}$.

\subsection{Excepción para alegar la inoponibilidad de los efectos derivados de la constitución del sindicato ilícito}

Es muy infrecuente que se alegue mediante una excepción interpuesta en la contestación de demanda la inoponibilidad del sindicato constituido con abuso del derecho o en fraude a la ley, toda vez, que el sindicato mismo o sus trabajadores no reclaman en sede judicial el reconocimiento del acto de constitución sindical propiamente tal, debido a que tal reconocimiento lo han obtenido con la inscripción en el registro de sindicatos que lleva la Inspección del Trabajo. Constatación que queda comprobada con el hecho que no existen pronunciamientos judiciales en que mediante una excepción de inoponibilidad se solicite la declaración de inoponibilidad del acto de constitución sindical. Sin embargo, es frecuente que el sindicato ilícito, alguno de los trabajadores constituyentes o la Inspección del Trabajo ejerzan en contra del empleador alguna acción judicial fundada en efectos derivados de un sindicato constituido con fines ilícitos, especialmente una acción de práctica antisindical o de nulidad del despido por infracción de las normas sobre fuero sindical, reclamando diversas prestaciones a través de dichas acciones. Acciones que se fundan en que el empleador no ha respetado las normas protectoras de la libertad sindical, especialmente las que regulan el fuero sindical, afectando al sindicato constituido con fines ilícitos, a sus directores sindicales y/o a sus trabajadores constituyentes.

Frente a las acciones ejercidas por los sujetos indicados el empleador dogmáticamente puede solicitar el rechazo de la acción ejercida, oponiendo una excepción perentoria que persiga enervarla, y a consecuencia de ello, solicitar el rechazo de la acción por la ineficacia del fuero, por serle inoponible el mismo. Nuestros Tribunales de Justicia en reiteradas oportunidades han rechazado la

\footnotetext{
${ }^{69}$ Segundo Juzgado de Letras del Trabajo de Santiago, RIT I-292-2011, 26 de enero de 2012; Segundo Juzgado de Letras del Trabajo de Santiago, RIT I-305-2011, 16 de febrero de 2012.
} 
acción de práctica antisindical ${ }^{70}$ y de nulidad del despido ${ }^{71}$, fundado en que el fuero sindical es ineficaz, porque emana de un sindicato constituido con abuso del derecho o en fraude a la ley, siendo contrario a la buena fe y a la primacía de la realidad.

\subsection{Procedimiento en que se ejerce la acción y la excepción fundada en un sindicato constituido con fines ilícitos}

En los supuestos en que se puede ejercer una acción de nulidad absoluta o de inoponibilidad del acto de constitución sindical, el procedimiento en que se conocerá dicha acción es el de aplicación general regulado en los artículos 446 y siguientes del Código del Trabajo. No lo será en un procedimiento monitorio ni tampoco en un procedimiento de tutela laboral, por la sencilla razón que no concurren los supuestos que hacen procedente dichos procedimientos. El procedimiento monitorio es de carácter excepcional, que solamente tiene cabida en determinados supuestos establecidos en el artículo 496 del Código del Trabajo, entre los que no se encuentran las acciones de inoponibiliad y de nulidad absoluta, cuya cuantía, por lo demás, es indeterminada. Por su parte, el procedimiento de tutela laboral igualmente procede en determinados casos, lo que ocurrirá cuando el empleador vulnere en el ejercicio de sus potestades legales alguno de los derechos fundamentales enumerados taxativamente en el artículo 485 del Código del Trabajo durante la vigencia de la relación laboral o bien con ocasión del despido, por tanto, tiene lugar cuando la víctima es el trabajador, el sujeto activo el empleador, y resultan vulnerados ciertos derechos fundamentales. Sin embargo, cuando existe un sindicato ilícito y se ejerce una acción de inoponibilidad o de nulidad absoluta en contra del mismo no concurre ninguno de los supuestos fácticos que hacen admisible el procedimiento de tutela laboral. De ahí que por ser el procedimiento de aplicación general el procedimiento que procede de forma general y subsidiaria, es en él donde deben tramitarse las acciones de nulidad absoluta y de inoponibilidad del sindicato constituido con fines ilícitos.

\footnotetext{
70 Séptimo Juzgado Laboral de Santiago, rol No 2893-2006, 28 de noviembre de 2008; Segundo Juzgado de Letras del Trabajo de Santiago, RIT S-41-2010, 23 de octubre de 2010; Primer Juzgado de Letras del Trabajo de Santiago, RIT S-44-2010, 9 de noviembre de 2010; Segundo Juzgado de Letras del Trabajo de Santiago, RIT S-50-2010, 30 de diciembre de 2010; sentencia de la I. Corte de Apelaciones de Santiago, rol № 2407-2010, 12 de enero de 2011; Segundo Juzgado de Letras del Trabajo de Santiago, RIT S-56-2011, 18 de noviembre de 2011; Primer Juzgado de Letras del Trabajo de Santiago, RIT S-106-2011, 23 de marzo de 2012.

${ }^{71}$ Corte de Apelaciones de Antofagasta, rol № 185-2007, 6 de diciembre de 2007; Cuarto Juzgado Laboral de Santiago, rol № 2803-2006, 26 de diciembre de 2008; Octavo Juzgado Laboral de Santiago, rol № 74-2007, 16 de junio de 2009; Corte de Apelaciones de Santiago, rol № 8465-2008, 30 de julio de 2009; Corte de Apelaciones de Santiago, rol № 755-2011, 19 de enero de 2012.
} 
Cuando la acción es de reclamo judicial de la resolución de multa aplicada a consecuencia de la inobservancia por parte del empleador de alguno de los efectos derivados del acto de constitución del sindicato ilícito, el procedimiento en que se conocerá será el de aplicación general o bien el monitorio, lo que dependerá de la cuantía de la multa según la regla establecida en el artículo 503 inciso $4^{\circ}$ del Código del Trabajo.

En cambio, si se alega la inoponibilidad o la nulidad absoluta del sindicato constituido con fines ilícitos o solamente la inoponibilidad de alguno de sus efectos a través de una excepción, el procedimiento en que se hará valer dependerá de la naturaleza de la acción ejercida fundada en un sindicato constituido con abuso del derecho o fraude a la ley, que se pretende enervar mediante la excepción. Así, si se ejerce una acción de nulidad del despido por infracción al fuero sindical emanado del acto de constitución sindical, el procedimiento puede ser el monitorio o el de aplicación general, dependiendo de la cuantía de lo demandado. En cambio, si se ejerce una acción de práctica antisindical o de tutela laboral fundado en el sindicato ilícito, el procedimiento es el de aplicación general con las reglas particulares previstas en los artículos 485 a 495 del Código del Trabajo, tratándose de la acción de tutela laboral, y artículos 292 al 294 bis del Código del Trabajo en relación a las normas del procedimiento de tutela laboral, en lo que dice relación con la acción de práctica antisindical.

\section{Sanción de los trabajadores dependientes que participan en la constitución de sindicatos ilícitos}

No existen dudas de que es reprochable la conducta del trabajador que interviene en la constitución de un sindicato con fines ilícitos, que está en pleno conocimiento de la naturaleza espuria del mismo, interviniendo en calidad de autor o cómplice en el mismo. Por el contrario, no lo es la del trabajador que de buena fe cree que está participando en la creación de un sindicato que persigue los fines que le son propios, pero que no es así por parte de la mayoría de los trabajadores constituyentes.

La gravedad de la conducta del trabajador varía dependiendo de su grado de participación en la constitución del sindicato ilícito como también de si se beneficia de las prerrogativas que derivan de la constitución de tal sindicato. Así, es posible que se haga elegir director o delegado sindical para beneficiarse del fuero sindical y de los permisos sindicales para su exclusivo provecho personal. Por su parte, si los permisos sindicales los paga el empleador e, incluso, los concede en forma superior a los que establece la ley, la conducta de los representantes de los trabajadores será más reprochable, debido a que el perjuicio causado al patrimonio del empleador es mayor como también el quebrantamiento de la confianza depositada en ellos, al utilizar los permisos concedidos y pagados 
para propósitos personales y no para realizar las actividades sindicales propias de un representante sindical.

La cuestión que corresponde determinar es si tratándose de los trabajadores dependientes que de mala fe participan en la constitución de un sindicato ilícito pueden ser sancionados por el empleador de modo ajustado a la ley. De ser así, corresponde determinar cuál es la sanción que procede aplicar.

La conducta de planificar y/o participar en la constitución de un sindicato ilícito con plena conciencia de la ilicitud merece sanción por parte del empleador aplicable a sus trabajadores dependientes en virtud del ejercicio de la potestad disciplinaria de que está dotado. Como la potestad disciplinaria está regida por el principio de tipicidad ${ }^{72}$, que viene a significar que las infracciones laborales deben estar previamente establecidas en normas legales, convencionales o reglamentarias y las sanciones en la ley ${ }^{73}$ o en el reglamento interno de la empresa, la sanción a aplicar debe necesariamente estar establecida en alguno de estos cuerpos normativos.

Sin embargo, debido a la complejidad de la organización de la empresa y la diversidad de deberes que deben observar los trabajadores, los cuales muchas veces se entienden implícitos en el contrato de trabajo, se admite la posibilidad que la tipificación de las infracciones no sea sumamente estricta, sino un tanto atenuada ${ }^{74}$. Por ello este principio no significa que deba existir una tipificación rígida y taxativa de las infracciones que limite por completo al empleador su facultad de valorar las conductas e incumplimientos de los trabajadores, puesto que, por un lado, resulta imposible predecir todos los comportamientos que puedan atentar contra el orden de la empresa, y por otro lado, la actividad empresarial implica una dinamicidad y agilidad necesaria para el mantenimiento de la misma en el actual mercado lleno de competitividad y adaptaciones a los cambios, que fijar un riguroso listado de faltas e infracciones laborales supondría congelar el estado de cosas en un determinado momento, sin posibilidad de tener en cuenta la multitud de acontecimientos y conductas que pueden concurrir en un caso concreto ${ }^{75}$. De esta manera, es frecuente que en los contratos individuales de trabajo, instrumentos colectivos de trabajo y normas internas de la empresa existan normas en blanco y cláusulas generales que desvirtúan en cierta medida la estricta tipificación de las infracciones laborales.

\footnotetext{
${ }^{72}$ Véase sobre el principio de tipicidad como límite de la potestad disciplinaria del empleador: FERNÁNDEZ (1991), pp. 153-175; GIl y GIL (1993), pp. 36-41; MaINARDI (2002), pp. 254-259; TerRadillos (2004), pp. 33-41; Poquet (2011), pp. 45-49; Fernández (2014 b), pp. 152-165.

73 Gamonal (2012), p. 103.

74 Fernández-Costales (2005), p. 56.

75 Fernández (1991), p. 171; Poquet (2011), p. 47.
} 
También debe observar el empleador el principio de proporcionalidad ${ }^{76}$ al momento de aplicar una sanción, que constituye otro límite del poder disciplinario $^{77}$. Este principio conlleva la obligación de ponderar la gravedad de la conducta del trabajador y los bienes jurídicos afectados, debiendo existir una debida proporción entre la sanción a aplicar y la conducta a sancionar ${ }^{78}$. Es obligatorio el examen individualizado en cada caso concreto donde han de ponderarse todos los elementos concurrentes en él, tanto subjetivos como objetivos: intención del infractor, circunstancias concurrentes, perjuicio al empleador, entre otros, de manera que sólo cuando la conducta del trabajador valorada, teniendo en cuenta todos los elementos de juicio dichos, constituye una infracción de la máxima gravedad resultando procedente el despido, que es también la sanción más grave establecida en el ámbito laboral. De este modo, el empresario sólo puede determinar la sanción concreta a imponer dentro del elenco correspondiente de acuerdo a la gravedad de la infracción concreta de las tipificadas, eliminando así toda posible arbitrariedad y cerrando la puerta a la absoluta decisión unilateral del empleador al momento de imponer la sanción ${ }^{79}$.

${ }^{76}$ Véase especialmente sobre el principio de proporcionalidad como límite del poder disciplinario del empleador: FernÁNDEZ (1991), pp. 277-279; LuJÁN (1997), pp. 23-27; LUQUe (1999), pp. 468-471; Mainardi (2002), pp. 306-321; TerRadillos (2004), pp. 41-48; RodríGuez (2008), pp. 192-206; Moreno (2009), pp. 255-265; Congeduti (2011), pp. 17-19; Fernández (2013), pp. 167-175; Fernández (2014 b), pp. 174-178.

77 La jurisprudencia judicial ha reconocido este límite en reiteradas oportunidades. Así se ha resuelto, tratándose de la justificación del despido: "CUARTO: [...] el sentenciador de fondo debe efectuar un juicio de proporcionalidad, conjugando diferentes variables que le permitan arribar a la convicción de que, por la entidad de las infracciones contractuales en que ha incurrido el dependiente, resulta de todo mérito sacrificar el vínculo contractual al nivel de su extinción. En tal caso, el tribunal se encuentra frente a dos polos que se contraponen, por un lado la innegable tendencia de todo nuestro sistema jurídico-laboral hacia la prolongación de la relación laboral en el tiempo, que se relaciona con el principio de relativa estabilidad en el empleo al que adscribe nuestro legislador; y por otro lado la extinción del vínculo sobre la base de haber existido un nivel de incumplimiento que logra poner en crisis el contrato, separando al trabajador de la empresa. En otras palabras, para que exista justa causa de despido, en estos casos, el juicio de proporcionalidad debe descartar todas las otras sanciones más benévolas que pudiere aplicar el empleador en ejercicio de sus facultades disciplinarias, y que deben consignarse en el respectivo reglamento interno" ( Corte de Apelaciones de La Serena, Rol Reforma Laboral No 54-2013, 1 de julio de 2013).

78 Fernández-Costales (2005), p. 57; Gamonal (2012), p. 103.

79 Se ha resuelto "SEXTO: Que, por último, contribuye a la interpretación o doctrina que sustenta el presente fallo el razonar, además, en el siguiente sentido: que si bien el legislador no precisa en el $N^{\circ} 1$ del precitado artículo 160 del Código Laboral, el grado o gravedad de la falta de probidad justificante del despido el que, por tratarse de una causal de caducidad, no da derecho a indemnización de perjuicios -la debida correspondencia y armonía entre todas las partes de una ley obliga a entender que debe existir una cierta proporcionalidad entre el quebrantamiento del deber impuesto al trabajador, y la drasticidad de la sanción aplicada. El estigma de haber perdido el trabajo por falta de probidad, implica una evidente privación futura de cualquiera otra contratación laboral. SEPTIMO: Que no concurre esta regla de proporcionalidad si la falta de probidad no acreditada probatoriamente en lo absoluto- es, en 
i) Considerando la conducta de mala fe, los intereses, los valores jurídicos y principios afectados con la constitución de un sindicato con abuso del derecho o en fraude a la ley, es claro que se trata de una de las conductas más graves en que puede incurrir un trabajador dependiente, por lo que se estima que es legalmente procedente el despido de esos trabajadores por alguna de las causales de caducidad establecidas en el artículo 160 del Código del Trabajo que es, precisamente, el precepto legal que regula las causales de despido aplicables por conductas imputables al trabajador. Al revisar la enumeración del artículo 160 la conducta del trabajador se encuadra, a nuestro entender, en la causal de la letra a) del $\mathrm{N}^{\circ} 1$ del artículo $160^{80}$, conforme a la cual el empleador podrá poner término al contrato individual de trabajo sin derecho a indemnización fundado en"[...] Alguna de las conductas indebidas de carácter grave, debidamente comprobadas, que a continuación se señalan: a) Falta de probidad del trabajador en el desempeño de sus funciones". Ello porque es evidente que no existe probidad ni honradez en la constitución de un sindicato con el único propósito de beneficiarse de las prerrogativas que derivan de su constitución para fines personales. Es así que existe una manifiesta carencia de integridad y honradez en el obrar de los trabajadores que constituyen un sindicato ilícito.

Se incurre por parte de los trabajadores en un comportamiento de mala fe, fraudulento, abusivo y carente de rectitud dentro del contrato de trabajo, constituyendo fundamento suficiente para poner término al contrato de trabajo, pues la honradez es inherente al comportamiento humano, debiendo entenderse incorporado al contrato de trabajo. El obrar honradamente no es más que una expresión del principio de buena fe que impera en el ámbito de las relaciones laborales, el cual deja de lado todo acto contractual jurídicamente reprochable.

Los Tribunales de Justicia nacionales han conocido de juicios de desafuero de representantes de los trabajadores, donde el empleador invocó la causal de falta de probidad del trabajador porque participaron en la constitución de un sindicato ilícito beneficiándose del fuero sindical y permisos sindicales con fines instrumentales. En un caso un trabajador se hizo elegir delegado sindical de un sindicato interempresas con el solo propósito de dejar sin efecto el despido de que había sido objeto por la causal de necesidades de la empresa. A consecuencia de ello logró la reincorporación a instancias de la Inspección del

todo caso, de muy escasa significación o importancia para los intereses patrimoniales de la empleadora, que ameriten la exoneración del trabajador, persona ésta que ha acreditado solvencia profesional y que siempre desempeñó su trabajo en conformidad a lo estipulado específicamente en su contrato", Corte de Apelaciones de Antofagasta, rol № 242-2005, 16 de enero de 2006. En similares términos Primer Juzgado de Letras del Trabajo de Santiago, RIT O-284-2010, 5 de mayo de 2010; Primer Juzgado de Letras del Trabajo de Santiago, RIT T-50-2010, 25 de junio de 2010.

80 Véase IRURETA (2011), pp. 361-397. 
Trabajo, quedando sin efecto el despido. Luego, en un breve lapso de tiempo fue elegido delegado sindical de otro sindicato interempresas para consolidar su inmovilidad en el trabajo. Debido a ello el empleador decidió iniciar un juicio de desafuero en contra del delegado sindical, solicitando autorización al tribunal competente para despedirlo por la causal del artículo $160 \mathrm{~N}^{\circ} 1$ letra a) del Código del Trabajo, el que fue acogido, toda vez que, en concepto del tribunal, la conducta del trabajador demandado careció de honradez, al obtener una calidad que la legislación laboral protege, en forma fraudulenta, abusiva y contraria a los fines del Derecho, y en específico, atentatoria del derecho de sindicación, con desviación del fin que el ordenamiento jurídico ha previsto, cual es la promoción y defensa de los intereses colectivos, conducta que, además, va en contra de la potestad legal del empleador de dirección, efectuada sólo con el objeto de enervar un despido, careciendo de título legítimo que le provea de estabilidad en el empleo ${ }^{81}$.

En otro caso, ciertos trabajadores planificaron la creación de un sindicato pagándole dinero a alguno de los trabajadores constituyentes, además de falsificar la firma y timbre del ministro de fe en el acta de constitución y estatutos, con el único fin de gozar de fuero sindical y permisos sindicales, haciéndose elegir para ello directores sindicales. Ante tal situación el empleador inició en contra de los dirigentes sindicales un juicio de desafuero por falta de probidad, el que fue acogido, debido a que la actuación de aquéllos en la formación del sindicato era contraria a la honradez y rectitud que toda persona debe presentar, en este caso, en su fuente laboral, aprovechándose de los efectos legales que significa ser dirigente sindical para fines personales y espurios ${ }^{82}$.

Sin embargo, el anterior no es el criterio uniforme en la jurisprudencia judicial, debido a que en un caso similar a los antes señalados se rechazó la demanda de desafuero sindical interpuesta por el empleador contra los trabajadores que falsificaron los actos de constitución del sindicato, fundado en que si bien pueden haber cometido una falta a la probidad, ella de manera alguna lo fue en el desempeño de sus funciones, tal como lo exige el artículo $160 \mathrm{~N}^{\circ} 1$ letra a) del Código del Trabajo ${ }^{83}$.

ii) Si existe reglamento interno en la empresa, y la conducta de participación en la constitución de sindicatos ilícitos está prevista en el mismo como una prohibición, sea expresamente o de modo implícito, el empleador podría no despedir a los trabajadores y aplicarles alguna de las sanciones tipificadas en el reglamento interno, que solamente pueden consistir en amonestación verbal

${ }^{81}$ Primer Juzgado de Letras del Trabajo de Santiago, RIT O-3499-2011, 20 de enero de 2012.

${ }^{82}$ Corte de Apelaciones de Santiago, Rol Reforma Laboral № 992-2012, 29 de octubre de 2012.

${ }^{83}$ Corte de Apelaciones de Santiago, Rol Reforma Laboral No 470-2013, 30 de abril de 2014. 
o escrita y multa de hasta el veinticinco por ciento de la remuneración diaria, tal como lo señala el artículo 154 N 10 del Código del Trabajo ${ }^{84}$. Sin embargo, debe tenerse presente que si decide aplicar alguna de las sanciones establecidas en el reglamento interno, no puede posteriormente despedir al trabajador por la misma conducta, debido a que lo impide el principio non bis idem, que constituye otro de los límites de la potestad disciplinaria del empleador ${ }^{85}$, toda vez que el empleador no puede sancionar una misma conducta dos o más veces respecto de un mismo sujeto y basado sobre un mismo fundamento ${ }^{86}$.

\section{Conclusiones}

Es posible observar que hay un estado de confusión en la jurisprudencia sobre los sindicatos constituidos con fines ilícitos, existiendo pronunciamientos contradictorios sobre los distintos aspectos de los mismos, pronunciamientos que han recaído principalmente en los juicios sobre sindicatos constituidos dentro de los diez días siguientes al despido de uno o más trabajadores constituyentes, comúnmente conocidos como "sindicatos del día después". No obstante lo anterior, se pueden extraer diversas conclusiones sobre cada uno de los aspectos tratados de los sindicatos constituidos con abuso del derecho y en fraude a la ley, a modo de resumen de la posición defendida en cada una de las cuestiones discutidas, cuyos fundamentos fueron expuestos en las secciones correspondientes.

El órgano competente para conocer de los juicios en que se discute la ilicitud del sindicato son los Juzgados de Letras del Trabajo, no los Juzgados Civiles. Tienen legitimidad para solicitar la sanción de dichos sindicatos la Inspección del Trabajo, el empleador, los trabajadores y las organizaciones sindicales, en la medida que tengan al menos un interés legítimo y actual.

Los instrumentos de que disponen los legitimados activos para solicitar la sanción de los sindicatos ilícitos son la acción y la excepción, ventilándose

\footnotetext{
${ }^{84}$ Dictamen de la Dirección del Trabajo No 4968/335, de 27 de noviembre de 2000.

${ }^{85}$ Véase especialmente sobre el principio non bis in idem como límite del poder disciplinario del empleador RodríGuez-Piñeiro (1990), p. 5; Fernández (1991), pp. 290-325; Luque (1999), pp. 487-49; Fernández-Costales (2005), pp. 58-60; Rodríguez (2008), pp. 216-224; Di Paola (2010), pp. 47-50; Poquet (2011), pp. 103-111; Fernández (2013), pp. 167-175; FerNández (2014 b), pp. 165-174.
}

${ }^{86}$ Segundo Juzgado de Letras del Trabajo de Santiago, RIT O-231-2009, 26 de noviembre de 2009; Segundo Juzgado de Letras del Trabajo de Santiago, RIT O-563-2009, 8 de enero de 2010; Segundo Juzgado de Letras del Trabajo de Santiago, RIT O-468-2009, 11 de enero de 2010; Segundo Juzgado de Letras del Trabajo de Santiago, RIT O-1064-2010, 26 de julio de 2010; Corte de Apelaciones de Santiago, Rol Reforma Laboral № 1846-2011, 29 de junio de 2012; Corte de Apelaciones de Santiago, Rol Reforma Laboral № 1070-2012, 6 de noviembre de 2012; Corte de Apelaciones de Santiago, Rol Reforma Laboral No 1644-2012, 27 de diciembre de 2012. 
su conocimiento en los procedimientos regulados en el libro $V$ del Código del Trabajo, lo que dependerá de la cuantía y naturaleza de la acción ejercida.

Los trabajadores dependientes que concurren a la constitución de un sindicato ilícito pueden ser sancionados por su empleador, lo que dependerá del mismo, al ser la potestad disciplinaria discrecional. Pero si la ejerce debe respetar los límites de dicha potestad, especialmente los principios de tipicidad, proporcionalidad y non bis in idem. Y conforme a los mismos, puede sancionar a los trabajadores que han incurrido en la conducta deshonesta con el despido de acuerdo a la causal del artículo 160 N 1 letra a) del Código del Trabajo o bien con amonestación verbal o escrita, o multa del 25\% de la remuneración diaria. Estas tres últimas sanciones sólo son procedentes en la medida que exista reglamento interno en la empresa y se encuentren reguladas en el mismo.

De persistir las decisiones contradictorias de los Tribunales de Justicia sobre los diversos aspectos de los sindicatos constituidos con fines ilícitos, que generan un estado de incertidumbre en los justiciables, resultará conveniente que el Poder Legislativo dicte las disposiciones legales pertinentes sobre la materia, con el propósito de lograr que los jueces tengan uniformidad de criterios al momento de resolver contiendas sobre los sindicatos con fines ilícitos, pues no resulta admisible que los jueces otorguen soluciones diversas, incluso a veces contradictorias, a contiendas iguales o similares sometidas a su conocimiento, al afectar la garantía de la igualdad ante la ley reconocida por la Constitución Política.

\section{BiBLIOGRAFÍA CITADA}

Alsina, Hugo (1941): Tratado Teórico Práctico de Derecho Procesal Civil y Comercial (Buenos Aires, Compañía Argentina de Editores), tomo I.

Abeliuk MANASEVICH, René (2003): Las Obligaciones, cuarta edición actualizada y aumentada (Santiago, Editorial Jurídica de Chile), tomo I.

Alessandri Besa, Arturo (2011) La Nulidad y la Rescisión en el Derecho Civil Chileno, reimpresión tercera edición (Santiago, Editorial Jurídica de Chile), tomo I.

Baylos, Antonio (2012): ¿Para qué sirve un sindicato? (Madrid, Catarata).

Barcia Lehmann, Rodrigo (2007): Lecciones de Derecho Civil Chileno. Del Acto Jurídico (Santiago, Editorial Jurídica de Chile), tomo I.

Bordalí Salamanca, Andrés (2011): "Análisis Crítico de la Jurisprudencia del Tribunal Constitucional sobre el Derecho a la Tutela Judicial", en: Revista Chilena de Derecho (volumen XXXVIII, № 2), pp. 311-337.

Calamandrei, Piero (1998): Derecho Procesal Civil (Ciudad de México, Editorial Jurídica Mexicana), volumen II.

Chiovenda, Giuseppe (2002): Instituciones de Derecho Procesal Civil (San José de Costa Rica, Editorial Jurídica Universitaria), volumen III. 
Congeduti, Mara (2011) "Il Procedimento Disciplinari: Elementi, Principi e Regole", en: Licenziamenti e Sanzioni nei Rapporti di Lavoro (Padova, Cedam), pp. 5-63.

Cordón Moreno, Faustino (1998): "Sobre la Legitimación en Derecho Procesal", en: Revista Chilena de Derecho (volumen XXV, № 2), pp. 357-385.

Couture, Eduardo (1981): Fundamentos del Derecho Procesal Civil (Buenos Aires, Ediciones Depalma).

Couture, Eduardo (1993): Vocabulario Jurídico (Buenos Aires, Depalma).

Devis Echandía, Hernando (1961): Tratado de Derecho Procesal Civil (Bogotá, Editorial Temis), tomo I.

Devis Echandía, Hernando (1966): Nociones Generales de Derecho Procesal Civil (Madrid, Aguilar).

Dı PAOlA, Luigi (2010): Il potere disciplinare nel lavoro privato e nel pubblico impiego privatizzato, seconda edizione (Milano, Giufré Editore).

Domínguez Águila, Ramón (1991): "Fraus Omnia Corrumpit. Notas sobre el Fraude en el Derecho Civil", en: Revista de Derecho Universidad de Concepción (No 189, año LIX), pp. 8-34.

Domínguez Águila, Ramón (1992): "Fraus Omnia Corrumpit. Notas sobre el Fraude en el Derecho Civil", en: Revista de Derecho y Jurisprudencia (tomo LXXXIX-No 3), pp. 73-96.

Domínguez ÁGuila, Ramón (2013): Teoría General del Negocio Jurídico, segunda edición Actualizada (Santiago, Editorial Jurídica de Chile).

Fernández-Costales, Javier (2005): Poder Disciplinario Empresarial y Proceso Especial de Impugnación de Sanciones (Oviedo, Consejo Económico y Social del Principado de Asturias).

FERNÁNDEZ LÓPEZ, María Fernanda (1982): El sindicato: naturaleza jurídica y estructura (Madrid, Editorial Civitas S.A.).

Fernández López, María Fernanda (1991): El Poder Disciplinario en la Empresa (Madrid, Editorial Civitas S.A.).

Fernández Toledo, Raúl (2011a): Las Facultades y Deberes del Juez en materia probatoria en el Proceso Laboral. Análisis crítico (Santiago, Punto Lex Thomson Reuters).

Fernández Toledo, Raúl (2011b): "Los Principios Dispositivo y Aportación de Parte en el Proceso Laboral. Su incidencia en la Iniciativa Probatoria Judicial", en: Revista Chilena de Derecho del Trabajo y Seguridad Social (volumen II, No 3), pp. 37-54.

FerNÁNDEZ Toledo, Raúl (2013): "Límites del poder disciplinario del empleador: principios non bis in idem y de proporcionalidad en la imposición de sanciones laborales", en: Revista Chilena de Derecho del Trabajo y Seguridad Social (volumen IV, № 8), pp. 167-175. 
FernÁNDEZ Toledo, Raúl (2014a): "Aproximación a la constitución de organizaciones sindicales con fines ilícitos", en: AA.VV., La organización sindical en Chile. XX Jornadas Nacionales de Derecho del Trabajo y de la Seguridad Social (Santiago, Librotecnia), pp. 265-309.

FerNÁNDEZ Toledo, Raúl (2014b): "La configuración del poder disciplinario del empleador en el ordenamiento laboral nacional", en: AA.VV., Estudios de regulación empresarial (Santiago, LegalPublishing-Thomson Reuters), pp. 135-197.

Gamonal Contreras, Sergio (2011): Derecho Colectivo del Trabajo, segunda edición revisada y actualizada (Santiago, Abeledo Perrot-LegalPublishing).

Gamonal Contreras, Sergio y Guidi Moggia, Caterina (2012): Manual del Contrato de Trabajo, tercera edición revisada y actualizada (Santiago, Abeledo Perrot-LegalPublishing).

García Pino, Gonzalo y Contreras Vásquez, Pablo (2013): "El derecho a la tutela judicial y el debido proceso en la jurisprudencia del Tribunal Constitucional chileno", en: Estudios Constitucionales (volumen XI, No 2), pp. 201-228.

GIL y GIL, José Luis (1993): Autotutela privada y poder disciplinario en la empresa (Madrid, Centro de Publicaciones del Ministerio de Justicia).

Guasp, Jaime y Argoneses, Pedro (2002): Derecho Procesal Civil, quinta edición (Madrid, Editorial Civitas S.A.).

IruReta Uriarte, Pedro (2012): "La Falta de Probidad como causa de extinción del Contrato de Trabajo", en: AA.VV., Estudios de Derecho del Trabajo y de la Seguridad Social. Tomo II (Santiago, Abeledo Perrot-LegalPublishing), tomo II, pp. 361-397.

LADARIA, Juan (1952): Legitimación y Apariencia Jurídica (Barcelona, Editorial Bosch).

Lanata Fuenzalida, Gabriela (2011): Manual de Proceso Laboral, segunda edición (Santiago, Abeledo Perrot-LegalPublishing).

Liebman, Enrico Tullio (1980): Manual del Derecho Procesal Civil (Traducc. Santiago Sentís Melendo, Buenos Aires, Ediciones Jurídicas Europa-América).

LuJÁN AlCARAZ, José (1997): "Algunas reflexiones sobre el principio de proporcionalidad en la calificación del despido", en: AA.VV., Cuestiones actuales sobre el despido disciplinario (Santiago de Compostela, Universidad Santiago de Compostela), pp. 23-32.

Luque Parra, Manuel (1999): Los Límites Jurídicos de los Poderes Empresariales en la Relación Laboral (Barcelona, J.M. Bosch Editor).

Macchiavello Contreras, Guido (1989): Derecho Colectivo del Trabajo. Teoría y Análisis de sus Normas (Santiago, Editorial Jurídica de Chile). 
MaInARDI, Sandro (2002): II potere disciplinare nel lavoro privato e pubblico. Art. 2106 (Milano, Guiffré Editore).

Maturana Miquel, Cristián (2000): Nociones Sobre Disposiciones Comunes a Todo Procedimiento (Santiago, Separata Departamento de Derecho Procesal, Facultad de Derecho Universidad de Chile).

Montero Aroca, Juan (2007): De la Legitimación en el Proceso Civil (Barcelona, Editorial Bosch S.A.).

Moreno De Toro, Carmen (2009): "Poder Disciplinario, Proporcionalidad y Discrecionalidad en la imposición de las Sanciones", en: Revista Temas Laborales (No 101), pp. 255-265.

Olavarría Rodríguez, Cristián (2013): "El abuso de derechos constitucionales y de la personalidad jurídica en materia laboral. Comentario a sentencia sobre el Sindicato del Día Después", en: Revista Actualidad Jurídica de la Universidad del Desarrollo (№ 27), pp. 503-511.

Poquet Catalá, Raquel (2011): La Actual Configuración del Poder Disciplinario Empresarial (Valencia, Tirant lo Blanch).

Prieto-Castro, Leonardo (1985): Tratado de Derecho Procesal Civil, segunda edición (Pamplona, Aranzadi).

Rodríguez-Piñeiro Royo, Miguel (1990): "Potestad Sancionadora y Non Bis in Idem", en: Revista Relaciones Laborales (№ 2), pp. 48-52.

Rodríguez Grez, Pablo (2004): Inexistencia y Nulidad en el Código Civil Chileno (Santiago, Editorial Jurídica de Chile).

Rodríguez Rodríguez, Emma (2008): El poder disciplinario y la negociación colectiva (Granada, Editorial Comares).

Romero Seguel, Alejandro (2006): Curso de Derecho Procesal Civil. La Acción y la Protección de Derecho (Santiago, Editorial Jurídica), tomo I.

Romero Seguel, Alejandro (2011): “La Acción para la Declaración de Inoponibilidad de un Acto o Contrato", en: AA.VV., Estudios de Derecho Privado. Libro homenaje al jurista René Abeliuk Manasevich (Santiago, Editorial Jurídica de Chile), pp. 251-264.

Sols Lucía, Alberto (1989): El Fraude a la Ley (Barcelona, Bosch S.A.).

Terradillos, Edurne (2004): El Poder Disciplinario Empresarial. Principios y Garantías (Valencia, Tirant lo Blanch).

Toledo Corsı, César (2013): Tutela de la Libertad Sindical (Santiago, Abeledo Perrot-LegalPublishing).

Varela Fleckenstein, Andrés (2009): "No más Solve et Repete en Procedimiento de Reclamación contra Resoluciones que imponen multas por infracción a la Legislación Laboral", en: Revista de Estudios Laborales ( $\left.N^{\circ} 4\right)$, pp. 141 160. 
Vescoví, Enrique (1984): Teoría General Del Proceso (Bogotá, Editorial Temis). Vial Del Río, Víctor (2003): Teoría General del Acto Jurídico, quinta edición actualizada (Santiago, Editorial Jurídica de Chile).

\section{JURISPRUDENCIA CITADA}

Reyes con Mindesa Ltda. (2006): Corte de Apelaciones de Santiago, 10 abril 2006, rol № 2105-2005 (acción de despido nulo). Disponible en: http:// laboral.poderjudicial.cl/SITLAPORWEB/InicioAplicacionPortal.do [visitado el 3/01/2013].

Dirección del Trabajo con Express de Santiago Uno S.A. (2007): Quinto Juzgado del Trabajo de Santiago, 5 de abril de 2007, rol № 2374-2006 (acción de práctica antisindical).

Dirección Regional del Trabajo de Atacama con Industrias Coemin S.A. (2007): Cuarto Juzgado de Letras de Copiapó, 3 de julio de 2007, rol № 368-2007 (acción de práctica antisindical).

Araya con CMS Tecnologías S.A. (2007): Corte de Apelaciones de Antofagasta, 6 diciembre 2007, rol No 185-2007 (acción de despido nulo). Disponible en: http://laboral.poderjudicial.cl/SITLAPORWEB/InicioAplicacionPortal.do [visitado el 19/03/2013].

Inspección del Trabajo con American Airlines (2008): Séptimo Juzgado Laboral de Santiago, 28 noviembre 2008, rol N L-2893-2006 (acción de práctica antisindical).

Arenas con Corporación Cultural de la llustre Municipalidad de Santiago (2008): Cuarto Juzgado Laboral de Santiago, 26 diciembre 2008, rol No L-2803-2006 (acción de nulidad del despido)

Vergara con American Airlines (2009): Octavo Juzgado Laboral de Santiago, 16 junio 2009, rol No L-74-2007 (acción de práctica antisindical).

Inspección Provincial del Trabajo de Valparaíso con Farmacias Cruz Verde S.A. (2009): Juzgado de Letras del Trabajo de Valparaíso, 20 de mayo de 2009, RIT S-4-2009 (acción práctica antisindical). Disponible en: http://laboral. poderjudicial.cl/SITLAPORWEB/InicioAplicacionPortal.do [visitado el 19/03/2014].

Inspección Provincial del Trabajo de Valparaíso con Farmacias Cruz Verde S.A. (2009): Juzgado de Letras del Trabajo de Valparaíso, 20 de mayo de 2009, RIT S-7-2009 (acción práctica antisindical). Disponible en: http://laboral. poderjudicial.cl/SITLAPORWEB/InicioAplicacionPortal.do [visitado el 19/03/2014].

Ávila con Schueftan Schwed (2009): Corte de Apelaciones de Santiago, 30 julio 2009, rol No 8465-2009 (acción de despido nulo). Disponible en http:// 
www.microjuris.cl/Search [visitado el 15/06/2013], identificador microjuris MJJ21184.

Inspección del Trabajo con SK Industrial S.A. (2009): Juzgado de Letras del Trabajo de Antofagasta, 13 noviembre 2009, RIT S-3-2009 (acción de práctica antisindical). Disponible en: http://www.microjuris.cl/Search [visitado el 15/06/2013], identificador microjuris MJJ22649.

Inspección del Trabajo con SK Industrial S.A. (2009): Juzgado de Letras del Trabajo de Antofagasta, 26 noviembre 2009, RIT S-4-2009 (acción de práctica antisindical). Disponible en: http://laboral.poderjudicial.cl/SITLAPORWEB/ InicioAplicacionPortal.do [visitado el 10/05/2013].

Inspección del Trabajo con SuBus Chile S.A. (2009): Segundo Juzgado de Letras del Trabajo de Santiago, 18 de diciembre de 2009, RIT T-26-2009 (acción de tutela laboral). Disponible en http://laboral.poderjudicial.cl/SITLAPORWEB/ InicioAplicacionPortal.do [visitado el 15/05/2013].

Segovia con Evaluadora Recourse Chile S.A. (2009): Segundo Juzgado de Letras del Trabajo de Santiago, 29 diciembre 2009, RIT O-348-2009 (acción de despido nulo). Disponible en: http://laboral.poderjudicial.cl/SITLAPORWEB/ InicioAplicacionPortal.do [visitado el 2/02/2013].

Opazo y otros con Subus Chile S.A. (2010): Segundo Juzgado de Letras del Trabajo de Santiago, 11 de enero de 2010, RIT T-43-2009 (acción de práctica antisindical). Disponible en: Disponible en: http://laboral.poderjudicial.cl/ SITLAPORWEB/InicioAplicacionPortal.do [visitado el 30/07/2014].

Inspección del Trabajo con Inversiones Gastronómicas S.A. (2010): Juzgado de Letras del Trabajo de Valdivia, 9 marzo 2010, RIT T-21-2009 (acción de tutela laboral). Disponible en: http://www.microjuris.cl/Search [visitado el 10/1/2013], identificador microjuris MJJ21184).

Opazo y otros con Subus Chile S.A. (2010): Corte de Apelaciones de Santiago, 16 de abril de 2010, Rol Reforma Laboral № 107-2010 (acción práctica antisindical). Disponible en: http://laboral.poderjudicial.cl/SITLAPORWEB/ InicioAplicacionPortal.do [visitado el 30/07/2014].

Segovia con Evaluadora Recourse Chile S.A. (2010): Corte de Apelaciones de Santiago, 7 junio 2010, Rol Reforma Laboral № 65-2010, (acción de despido nulo). Disponible en: http://laboral.poderjudicial.cl/SITLAPORWEB/ InicioAplicacionPortal.do [visitado el 20/02/2013].

Inspección del Trabajo con Servicio de Transporte de Personas Santiago S.A. (2010):

Primer Juzgado de Letras del Trabajo de Santiago, 30 julio 2010, RIT S-27-2010 (acción de práctica antisindical). Disponible en: http://laboral.poderjudicial. cl/SITLAPORWEB/InicioAplicacionPortal.do [visitado el 3/01/2013].

Soto con Redbus Urbano S.A. (2010): Segundo Juzgado de Letras del Trabajo de Santiago, 23 octubre 2010, RIT S-41-2012 (acción de práctica antisindical). 
Disponible en http://laboral.poderjudicial.cl/SITLAPORWEB/InicioAplicacionPortal.do [visitado el 24/12/2012].

Inspección del Trabajo con Ward Van Lines S.A. (2010): Primer Juzgado de Letras del Trabajo de Santiago, 9 noviembre 2010, RIT S-44-2010 (acción de práctica antisindical). Disponible en http://laboral.poderjudicial.cl/SITLAPORWEB/InicioAplicacionPortal.do [visitado el 15/12/2013].

Casino de Juegos de Valdivia S.A. con Sindicato de Empresa (2010): Juzgado de Letras del Trabajo de Valdivia, 13 noviembre 2010, RIT O-117-2010 (acción de nulidad absoluta del acto constitución del sindicato demandado). Disponible en: http://laboral.poderjudicial.cl/SITLAPORWEB/InicioAplicacionPortal.do [visitado el 10/10/2013].

Sindicato Interempresa con Montecarlo Administradora S.A. (2010): Segundo Juzgado de Letras del Trabajo de Santiago, 30 diciembre 2010, RIT S-50-2010 (acción de práctica antisindical). Disponible en: http://laboral.poderjudicial. cl/SITLAPORWEB/InicioAplicacionPortal.do [visitado el 5/06/2013].

Casino de Juegos de Valdivia S.A. con Sindicato de Empresa (2010): Corte de Apelaciones de Valdivia, 13 noviembre 2010, Rol Reforma Laboral № 2132010 (acción de nulidad absoluta del acto constitución del sindicato demandado). Disponible en: http://laboral.poderjudicial.cl/SITLAPORWEB/ InicioAplicacionPortal.do [visitado el 10/10/2013].

Riveros con A.F.P. Cuprum S.A. (2011): Corte de Apelaciones de Santiago, 12 enero 2011, rol No 2407-2010 (acción de práctica antisindical). Disponible en: http://laboral.poderjudicial.cl/SITLAPORWEB/InicioAplicacionPortal.do [visitado el 5/06/2013].

Inspección del Trabajo Santiago - Maipo con Sociedad Educacional e Inversiones Araya S.A. y otra (2011): Juzgado de Letras del Trabajo de San Miguel, 17 de agosto de 2011, RIT S-3-2011 (acción de práctica antisindical). Disponible en: http://laboral.poderjudicial.cl/SITLAPORWEB/InicioAplicacionPortal.do [visitado el 30/07/2014].

Farmacia Cruz Verde S.A. con Sindicato de Establecimiento de Empresa Cruz Verde S.A. (2011): Corte de Apelaciones de Talca, 29 de septiembre de 2011, Rol Reforma Laboral № 87-2011 (acción nulidad constitución sindicato). Disponible en: http://laboral.poderjudicial.cl/SITLAPORWEB/InicioAplicacionPortal.do [visitado el 5/07/2013].

Villalobos con Inversiones Alsacia S.A. (2011): Segundo Juzgado de Letras del Trabajo de Santiago, 18 noviembre 2011, RIT S-56-2011 (acción de práctica antisindical). Disponible en: http://laboral.poderjudicial.cl/SITLAPORWEB/ InicioAplicacionPortal.do [visitado el 5/06/2013].

Inversiones Alsacia S.A. con Villalobos (2011): Segundo Juzgado de Letras del Trabajo de Santiago, 18 noviembre 2011, RIT O-2574-2011 (acción de 
mera certeza del despido). Disponible en: http://laboral.poderjudicial.cl/ SITLAPORWEB/InicioAplicacionPortal.do [visitado el 5/06/2013].

Yáñez con AFP Provida S.A. (2012): Corte de Apelaciones de Santiago, 19 enero 2012, rol No 755-2011 (acción de despido nulo). Disponible en http:// www.microjuris.cl/Search [visitado el 15/03/2013], identificador microjuris MJJ22649.

Express de Santiago Uno S.A. con Inspección del Trabajo (2012): Segundo Juzgado de Letras del Trabajo de Santiago, 26 enero 2012, RIT I-2922011 (acción de reclamo judicial de multa). Disponible en: http://laboral. poderjudicial.cl/SITLAPORWEB/InicioAplicacionPortal.do [visitado el 5/12/2013].

Express de Santiago Uno S.A. con Inspección del Trabajo (2012): Segundo Juzgado de Letras del Trabajo de Santiago, 16 febrero 2012, RIT I-305-2011 (acción de reclamo judicial de multa). Disponible en: http://laboral.poderjudicial.cl/SITLAPORWEB/InicioAplicacionPortal.do [visitado el 5/12/2013].

Muñoz con Express Santiago Uno S.A. (2012): Primer Juzgado de Letras de Santiago, 23 marzo 2012, RIT S-106-2011 (acción de práctica antisindical). Disponible en: http://laboral.poderjudicial.cl/SITLAPORWEB/InicioAplicacionPortal.do [visitado el 5/12/2013].

Ceballos con Express de Santiago Uno S.A. (2012): Corte de Apelaciones de Santiago, 6 de julio de 2012, Rol Reforma Laboral № 591-2012 (acción nulidad despido). Disponible en: http://laboral.poderjudicial.cl/SITLAPORWEB/ InicioAplicacionPortal.do [visitado el 5/07/2014].

Transportes Corvalán y Cía. Ltda. con Sindicato de Empresa Transportes Corvalán y Cía. Ltda. (2013): Juzgado de Letras de Santiago, 30 mayo 2013, RIT O-45-2013 (acción de nulidad constitución sindicato). Disponible en: http:// laboral.poderjudicial.cl/SITLAPORWEB/InicioAplicacionPortal.do [visitado el 30/07/2014].

Buses Metropolitana S.A. con Escobedo y otros (2014): Corte de Apelaciones de Santiago, 30 de abril de 2014, Rol Reforma Laboral № 470-2013 (acción desafuero sindical). Disponible en: http://laboral.poderjudicial.cl/ SITLAPORWEB/InicioAplicacionPortal.do [visitado el 30/07/2014].

Jumbo Administradora Norte Ltda. con Inspección Provincial del Trabajo El Loa Calama (2014): Corte de Apelaciones de Antofagasta, 13 mayo 2014, rol No 17-2014 (acción de reclamo judicial de multa). Disponible en: http:// laboral.poderjudicial.cl/SITLAPORWEB/InicioAplicacionPortal.do [visitado el 30/07/2014]. 